\title{
The Dynamic Interplay Between Cardiac Inflammation and Fibrosis
}

\author{
Toby P. Thomas and Laurel A. Grisanti* \\ Department of Biomedical Sciences, College of Veterinary Medicine, University of Missouri, Columbia, MO, United States
}

Heart failure is a leading cause of death worldwide. While there are multiple etiologies contributing to the development of heart failure, all cause result in impairments in cardiac function that is characterized by changes in cardiac remodeling and compliance. Fibrosis is associated with nearly all forms of heart failure and is an important contributor to disease pathogenesis. Inflammation also plays a critical role in the heart and there is a large degree of interconnectedness between the inflammatory and fibrotic response. This review discusses the cellular and molecular mechanisms contributing to inflammation and fibrosis and the interplay between the two.

Keywords: cardiac, fibrosis, fibroblast, inflammation, leukocyte, cytokine

\section{INTRODUCTION}

OPEN ACCESS

Edited by:

Markus Wallner,

Medical University of Graz, Austria

Reviewed by:

Bing Hui Wang,

Monash University, Australia

Thomas Langenickel,

Ethris GmbH, Germany

${ }^{*}$ Correspondence:

Laurel A. Grisant grisanti@missouri.edu

Specialty section:

This article was submitted to Integrative Physiology,

a section of the journal

Frontiers in Physiology

Received: 22 January 2020

Accepted: 14 August 2020

Published: 15 September 2020

Citation:

Thomas TP and Grisanti LA (2020) The Dynamic Interplay Between Cardiac Inflammation and Fibrosis.

Front. Physiol. 11:529075. doi: 10.3389/fphys.2020.529075
Cardiovascular disease is the leading cause of death worldwide and represents an immense health and economic burden (Benjamin et al., 2019). It is comprised of a group of conditions affecting the blood vessels and heart, culminating in impaired cardiovascular performance. Heart failure, the clinical manifestation of cardiovascular disease, is characterized by fibrosis, chamber remodeling and a reduction in ventricular compliance. Cardiomyocytes have limited capacity for regeneration thus, injury to the heart, leading to death of cardiomyocytes, results in clearing of dead cardiomyocytes and repair through fibrotic scar tissue replacement. This helps maintain the structural and functional integrity of the heart, but results in impairments in contractility and cardiac function when excessive. Ischemic heart disease is the leading type of cardiovascular disease and results in a fibrotic scar, however, fibrosis is a major contributor to many forms of heart disease and is recognized as a pathological hallmark in the heart (Travers et al., 2016).

Inflammation is a major regulator of the reparative response after cardiac injury. Following injury, there is an acute, intense inflammatory response that is important for initiating healing (Prabhu and Frangogiannis, 2016). Later immune responses promote repair. Proper timing and magnitude of inflammatory responses is critical for normal healing. Persistent inflammation can promote further tissue destruction while insufficient responses prolong the injurious stimuli. Inflammation regulates all aspects of cardiovascular health including cardiac fibrosis. There is a high degree of interconnectedness between immune cells and fibroblasts with each regulating the other's function. While recently these responses have been increasingly studied, inflammatory events that occur in the heart continue to not be fully understood. This further need to understand the mechanisms of cardiac repair is exemplified by the fact that no large-scale immunomodulatory or anti-inflammatory therapeutic strategies have been successfully translated into clinical practice.

\section{CARDIAC FIBROSIS}

Cardiac fibrosis is the process of pathological extracellular matrix (ECM) remodeling resulting in abnormal matrix composition leading to impairments in cardiac contractility and function. 
Fibrosis is involved in nearly all types of heart disease including various ischemic and non-ischemic etiologies (Liu et al., 2017). Initially, ECM deposition is protective and important for wound healing, but excessive or prolonged deposition can lead to impairments in tissue function. Fibrosis leads to a stiffer and less compliant heart, ultimately contributing to the progression of heart failure.

In the mammalian adult heart, cardiomyocytes are organized in a network of parenchymal cells, which includes a large number of fibroblasts, and ECM proteins. The ECM is composed predominantly of fibrillary collagens with type I collagen being the predominant form and type III collagen representing a smaller fraction along with other proteins such as fibronectin and elastin (Rienks et al., 2014). The ECM serves as a scaffold for cells and is also important in transmission of contractile forces in the normal myocardium.

Cardiac fibroblasts are the predominant cell type involved in cardiac fibrosis. They reside in the interstitium, epicardial and perivascular regions of the heart. Studies assessing fibroblast numbers have varied depending on species, technique and markers used, but regardless, it is appreciated that there is an abundant fibroblast population in the heart (Nag, 1980; Banerjee et al., 2007). Due to a lack of fibroblast specific markers, studies involving fibroblast have been difficult and likely represent a heterogeneous population of cells and numbers likely vary depending on the species studied, age and gender (Nag, 1980; Camelliti et al., 2005; Banerjee et al., 2007).

While fibroblasts are plentiful in the non-pathological heart, their function remains poorly understood. Resident fibroblasts originate from the embryonic epicardium (Gittenberger-de Groot et al., 1998). Under normal conditions, fibroblasts contribute to the homeostasis of the heart through the contribution of ECM, which serves as a structural scaffold for cardiomyocytes, distributes mechanical forces and mediates electrical conduction (Travers et al., 2016). Fibroblasts also contribute to matrix remodeling through the production of ECM regulatory proteins including the matrix metalloproteinases (MMPs) and TIMPs. Fibroblasts also have the ability to rapidly respond to alterations in their microenvironment. They are networked into the interstitial and perivascular matrix putting them in a strategic location for serving as sentinel cells to sense injury and trigger reparative responses (Kawaguchi et al., 2011; Diaz-Araya et al., 2015).

In the healthy heart, resident fibroblasts remain in the quiescent state, however, during pathological conditions, these resident fibroblasts and other precursor cells become activated and transdifferentiate into myofibroblasts. The origin of activated cardiac myofibroblasts is less clear with potential sources include resident fibroblasts, vascular endothelium, epicardium, perivascular cells and hematopoietic bone marrow-derived progenitor cells. There is substantial evidence that resident fibroblasts proliferate and activate in response to pathological stimuli (Fredj et al., 2005; Teekakirikul et al., 2010; Ali et al., 2014; Moore-Morris et al., 2014) however, these studies do not discount the possibility of other sources of activated fibroblasts. With the advent of transgenic mouse models, lineage tracing studies are beginning to be used to address this question.
Endothelial, epicardial and perivascular cells have been proposed to undergo an endothelial-mesenchymal transition to acquire a fibroblast, pro-fibrotic phenotype. Lineage tracing studies have been performed to identify the contribution of these cell populations to the fibroblast population after injury however, many of the markers used such as Tie 2 and vascular endothelial cadherin are not specific to the cell population being studied and immune cells express many of these same markers (Kisanuki et al., 2001; Monvoisin et al., 2006; Zeisberg et al., 2007; Russell et al., 2011; Ali et al., 2014; Kramann et al., 2015). Similarly, hematopoietic bone marrow-derived progenitor cells have also been proposed as a potential source of fibroblasts during pathology. This is due to initial studies using GFP-labeled bone marrow transplants where a large number of GFP-positive cells were located in fibrotic regions after pressure overload and myocardial ischemia (Haudek et al., 2006; Zeisberg et al., 2007; van Amerongen et al., 2008). However, these findings may be due to the presence of inflammatory cells in the fibrotic region and not a transition of these cell populations into myofibroblasts (Yano et al., 2005; van Amerongen et al., 2007). Regardless, CD45-positive cells including monocytes can express myofibroblast markers (Haudek et al., 2006) and it is known that inhibition of monocyte recruitment diminishes the cardiac fibroblast population (van Amerongen et al., 2007). Whether this is due to the importance of early immune responses in the recruitment and activation of fibroblast populations is unknown. However, lineage tracing experiments using the Vav-Cre and other lines suggest minimal contribution of hematopoietic cells to the cardiac fibroblast population (Ali et al., 2014; Moore-Morris et al., 2014, 2018).

The identification of fibrocytes in the circulation has renewed the interest of cells of hematopoietic origin as potential fibroblast contributors (Bucala et al., 1994). Fibrocytes are a unique fibroblast progenitor population that expresses fibroblast markers such as pro-collagen I and vimentin as well as hematopoietic markers (Abe et al., 2001). They originate from hematopoietic stem cells and have been shown to contribute to cardiac fibrosis in several injury models (Mollmann et al., 2006; Zeisberg et al., 2007; Xu et al., 2011).

Regardless of their origin, myofibroblasts appear shortly after injury and have a fibroblast-smooth muscle cell phenotype, with the acquisition of $\alpha$-smooth muscle actin, contractile functions and enhanced secretion of collagens and other ECM components to promote scar formation. In accordance with their hypothesized sentinel cell function, following insult or injury, there is an upregulation of pro-inflammatory and profibrotic factors in cardiac fibroblasts, which culminates in increases in fibroblast proliferation and the transition to a myofibroblast phenotype.

Myofibroblasts are the major cell type responsible for ECM and secretion. They are characterized by the development of stress fibers and expression of contractile proteins such as $\alpha$-smooth muscle actin (Frangogiannis et al., 2000b; Santiago et al., 2010). Myofibroblasts secrete collagen and other ECM proteins to preserve the structural integrity of the heart. Failure of the heart to adapt and meet the pressure-generating capacity results in myocardial dysfunction and rupture. After 
ECM deposition, the tensile strength increases at the site of injury leading to mature scar formation. While these processes are initially adaptive, they can lead to the development of adverse changes in compliance and structure, worsening the progression of heart failure over time. Pathological remodeling is characterized by fibroblast accumulation and excessive ECM deposition. This leads to alterations in the heart's architecture and has additional consequences on cardiac function. Fibrosis damages cardiac function due to the increased stiffness in the ventricle, producing contractile impairments. ECM and fibroblasts can disrupt the mechano-electric coupling of cardiomyocytes, diminishing cardiac contraction and increasing the risk of arrhythmia. Paracrine signaling from fibroblasts can induce hypertrophy and further cardiac dysfunction. Additionally, apoptosis resistant myofibroblasts can reside in mature scars perpetuating these responses.

Cardiac fibrosis presents itself in three forms: perivascular, reactive interstitial, and replacement fibrosis (Anderson et al., 1979), which are exemplified in Figure 1. Reactive interstitial fibrosis is adaptive to preserve cardiac structure and function whereas replacement fibrosis fills areas cause by cardiomyocyte death. Perivascular fibrosis, often occurring with other forms of fibrosis, is characterized by increased collagen deposition around vessels and microvasculature which function to provide oxygen and nutrients to cardiac tissue (Ytrehus et al., 2018). Perivascular fibrosis is heavily involved in hypertension and leads to impaired blood flow hampering the delivery of oxygen and nutrients to potentiate a pathogenic response (Kai et al., 2006). Pressure overload models, such as transaortic constriction, have a period of reactive interstitial fibrosis while the heart adapts to the hemodynamic changes followed by replacement fibrosis upon cardiomyocyte death. During myocardial infarction or ischemia/reperfusion injury, where there is an acute, extensive cardiomyocyte death, replacement fibrosis occurs, which fills the region devoid of cardiomyocytes and prevent cardiac rupture.

Fibrosis is also an essential aspect of cardiac repair. Initially it is a protective process and acts to preserve the architecture of the heart through the deposition of connective tissue. However, fibrosis can become pathological when progressive and excessive, leading to aberrant scarring, further organ damage and impairments in cardiac function. Ischemic diseases, hypertension, valvular disorders, and primary/secondary cardiomyopathies all include at least one of the three types of fibrosis and ECM remodeling (Burt et al., 2014). As the heart adopts a pathologic state, ECM remodeling and excessive fibrosis in turn lead to changes in chamber dimension and in some cases cardiomyocyte hypertrophy. As the injured healing heart adjusts to meet the demands of the rest of the body the myocardium around the fibrotic scar dilates. The progressive increased load on the heart causes a further dilation of the left ventricle, thereby increasing ventricular cavity size. Due to the naturally quiescent non-proliferative state of cardiomyocytes, existing viable cardiomyocytes undergo hypertrophy to account for an increased volume load. These changes lead to progressive ECM remodeling and interstitial fibrosis resulting in decompensated heart failure.

\section{INFLAMMATION IN THE HEART}

Inflammation is an important defense mechanism that acts to remove harmful stimuli and promote recovery. While some wound healing and fibrotic processes can occur in the absence of cellular immunity, inflammation is an important contributor to cardiac health both in the normal and diseased state. Inflammation of the appropriate timing, duration and magnitude is critical for normal healing. Failure to activate sufficient inflammatory responses can lead to persistence of the injurious stimuli whereas failure to resolve inflammation can further tissue destruction.

Under non-pathological conditions, cardiac macrophages and other resident immune populations help regulate homeostasis. While the role of immune responses in cardiac homeostasis has been an understudied area, it is known that the heart has resident populations of mast cells and macrophages that play an important role in homeostasis and following injury (Sperr et al., 1994; Frangogiannis et al., 1999). There are also small populations of $\mathrm{B}$ and $\mathrm{T}$ cells present in the healthy myocardium (Pinto et al., 2016). Under steady-state conditions, resident immune cells are believed to play a sentinel role in surveilling against invading pathogens, similar to what is observed in other tissues (Franken et al., 2016). Mast cells are located in the perivascular areas and contain stores of inflammatory mediators such as tumor necrosis factor (TNF), histamine and tryptase, which can be quickly released following injury and represent an important contributor to triggering inflammatory responses (Frangogiannis et al., 1998a; Somasundaram et al., 2005).

The heart also contains resident macrophage populations that are comprised primarily of CCR2- cells of embryonically derived cells that originate from yolk sac macrophages and fetal monocytes (Pinto et al., 2012; Epelman et al., 2014; Heidt et al., 2014; Mylonas et al., 2015). There is also a small population derived from CCR2 + monocytes. Some studies suggest that resident cardiac macrophages die following injury and are replaced by monocyte-derived CCR2-expressing populations that are highly pro-inflammatory (Heidt et al., 2014). Outside of pathogen surveillance, resident immune populations are hypothesized to facilitate physiological turnover of cells and ECM, debris clearance after changes in metabolic load, and also play a role in the conduction system (Swirski et al., 2009). Gene expression profiling has identified distinct profiles of CCR2macrophages in human myocardium compared to CCR2+ populations with enhanced expression of pathways involved in cell growth and ECM formation (Bajpai et al., 2018). While functional outcomes of these differences of these gene expression differences is not well characterized, these findings are consistent with the role of resident macrophage populations in other tissues (Franken et al., 2016). Outside of the classic role of tissue macrophages, cardiac macrophages have also been recognized as having organ-specific functions. Resident cardiac macrophages are enriched in the conduction system of the heart and depletion disrupts electrical conduction in the heart (Hulsmans et al., 2017). These studies have identified a relationship between cardiomyocytes and macrophages through the formation of 

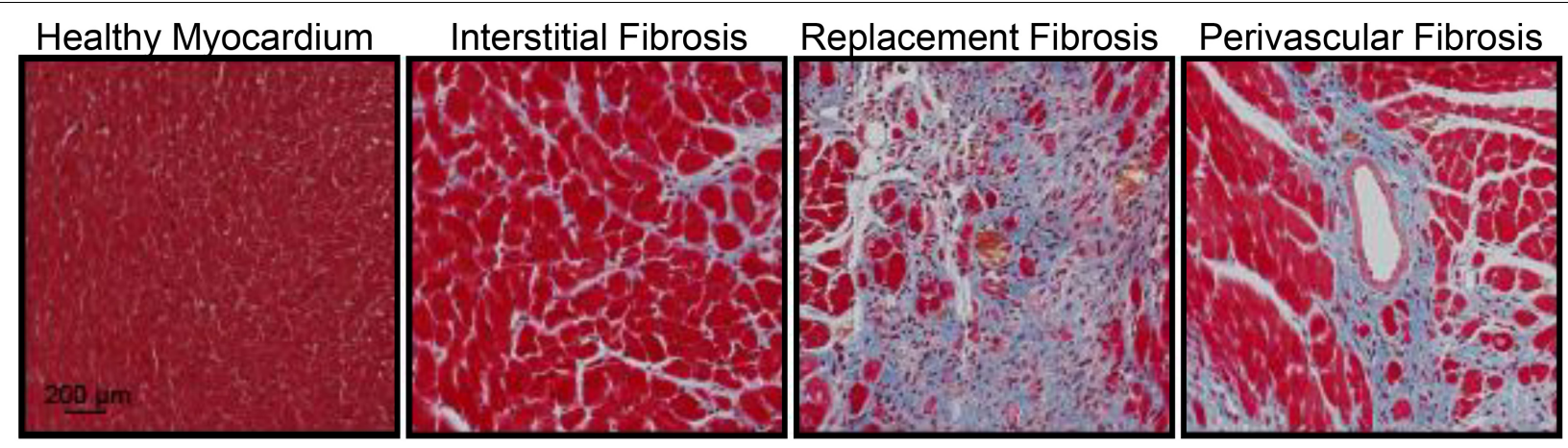

FIGURE 1 | Masson's trichrome staining of the mouse heart demonstrating fibrosis (blue) in the healthy myocardium, interstitial fibrosis following isoproterenol administration (30 mg/kg/d for 2 weeks), replacement fibrosis after myocardial infarction (4 weeks) or perivascular fibrosis following isoproterenol infusion (30 mg/kg/d for 2 weeks). Red represents the cytoplasm and black represent nuclei. Animal procedures were performed in house with approval by the Institutional Animal Care and Use Committee at the University of Missouri and in accordance to the National Institutes of Health Guidelines on the Use of Laboratory Animals.

gap junctions that enable cardiac macrophages to contribute to steady-state electrical conduction.

Pathologically, inflammation regulates virtually all aspects of cardiovascular health including cardiomyocyte contractility and cardiac fibrosis and represents an important regulatory mechanism. Following injury, acute inflammatory responses occur that help remove dead or damaged cardiomyocytes, ECM debris and initiate healing. Cardiac repair after injury is a finely tuned and regulated series of events that is critical for adequate healing (Figure 2). With the exception of myocarditis, other forms of cardiac injury are considered sterile inflammation and follow a similar series of events. This progression of events has been well defined for myocardial infarction and include the inflammatory, proliferative and maturation phases (Prabhu and Frangogiannis, 2016). While these responses may not be identical in timing, duration and magnitude between heart failure etiologies, they are thought to be broadly applicable to other forms of sterile cardiac damage (Fildes et al., 2009). Following insult or injury, there is an acute inflammatory phase characterized by infiltration of pro-inflammatory immune cell populations that digest and clear damaged cells and ECM tissue. This is followed by a reparative phase with the resolution of pro-inflammatory responses and activation of reparative responses such as myofibroblast accumulation, ECM deposition and neovascularization. Appropriate magnitude and duration of each event is critical for optimal repair. Early inflammatory activation is needed for the transition to a reparative response whereas an excessive inflammatory phase can further tissue damage and lead to improper healing.

\section{THE INFLAMMATORY PHASE}

The inflammatory phase is characterized by the recruitment of inflammatory cells to the site of damage (Prabhu and Frangogiannis, 2016). Cardiomyocytes are more susceptible to ischemic injury or damage than non-cardiomyocytes. Injury or death of cardiomyocytes causes the release of danger-associated molecular patterns (DAMPs) that bind to a cognate pattern recognition receptor (PRR) on neighboring cells to initiate inflammatory responses (Figure 3). A number of factors released from damaged or dying cardiomyocytes have been identified as DAMPs including mitochondrial DNA (Bliksoen et al., 2016), the chromatin protein high mobility group box 1 (HMGB1) (Lotze and Tracey, 2005), purine metabolites (Kono et al., 2010; McDonald et al., 2010), sarcomeric protein fragments (Lipps et al., 2016), and S100 proteins (Rohde et al., 2014). Additionally, fragments of the ECM that arise from damage including biglycan (Schaefer et al., 2005), decorin (Merline et al., 2011), hyaluronan (Scheibner et al., 2006) and fibronectin (Gondokaryono et al., 2007; Lefebvre et al., 2011; Sofat et al., 2012) have been shown to activate PRRs to contribute to inflammatory responses.

DAMP activation of PRRs induces the production of a cascade of inflammatory mediators including cytokines, chemokines and cell adhesion molecules (Mann, 2011). PRRs are present on cells of the innate immune system but can also act on surviving resident cell populations including cardiomyocytes (Kukielka et al., 1993; Frantz et al., 1999; Tarzami et al., 2002), fibroblasts (Zhang et al., 2015; Turner, 2016) and endothelial cells (Kumar et al., 1997) to potentiate the inflammatory cascade (Frantz et al., 1999). The best characterized family of PRRs are the Toll-like receptors (TLR) but others include nucleotide-binding oligomerization domainlike receptors (NLRs) and receptor for advanced glycation end-products (RAGE). Signal transduction by PRRs has been extensively delineated and converges on the activation of mitogen-activated protein kinases (MAPKs) and nuclear factor $(\mathrm{NF})-\kappa \mathrm{B}$ to regulate the expression of a large panel of pro-inflammatory genes including cytokines, chemokines and adhesion receptors (Akira and Takeda, 2004). These factors enhance leukocyte recruitment to amplify the inflammatory response, promote efferocytosis of dying cells and augment tissue digestion by proteases and oxidases.

Due to their close proximity, wide distribution in the myocardium, ability to rapidly respond to stimuli and potential as a source of inflammatory mediators, fibroblasts have been proposed to serve as sentinel cells in the heart. Within days of tissue damage, cardiac fibroblasts acquire a 

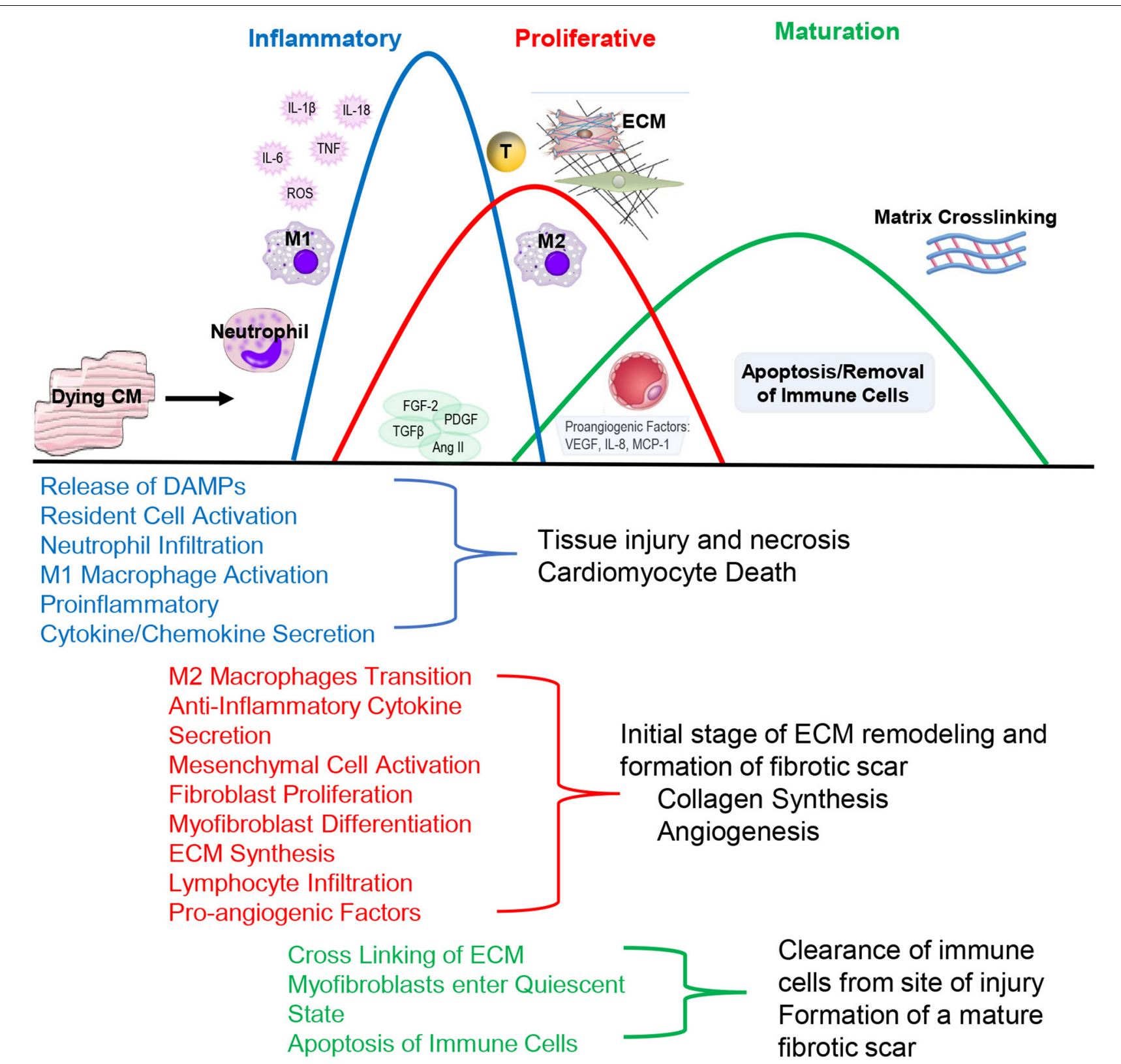

FIGURE 2 | During the Inflammatory Phase, damage or death of cardiomyocytes activates resident fibroblasts and other cell populations to produce cytokines and recruit pro-inflammatory leukocyte populations, primarily neutrophils and monocytes that differentiate into M1-like macrophages. This acute, pro-inflammatory response transitions into a reparative response during the Proliferative Phase with the recruitment of reparative lymphocyte and M2-like macrophages populations. Activated myofibroblasts secrete collagen and other extracellular matrix components. Pro-angiogenic factors are secreted that promote neovascularization. The events conclude during the Maturation Phase with the apoptosis of reparative immune cell and myofibroblast populations and matrix crosslinking, resulting in mature scar formation.

pro-inflammatory phenotype characterized by the secretion of cytokines/chemokines including IL-8, IL-1 $\beta$, CCL2, eotaxin and TNF- $\alpha$ and the presence of matrix-degrading properties (Sandanger et al., 2013; Sandstedt et al., 2019). The inflammatory potential of cardiac fibroblasts has been extensively documented in vitro (Heim et al., 2000; Lafontant et al., 2006). Stimulation of cardiac fibroblasts with ATP results in a large release of pro-inflammatory cytokines (Lu et al., 2012). A number of different factors in addition to ATP are also known to cause fibroblast activation including reactive oxygen species (ROS) (Siwik et al., 2001; Lijnen et al., 2006; Lu et al., 2012) and cytokines (Lafontant et al., 2006; Zymek et al., 2007; Turner et al., 2009). Cytokines have been implicated in inducing an inflammatory phenotype in cardiac fibroblasts and potentiating cytokine and chemokine synthesis (Lafontant et al., 2006; Zymek et al., 2007; Turner et al., 2009). They have also been shown to 


\section{Dying or stressed cardiomyocyte}

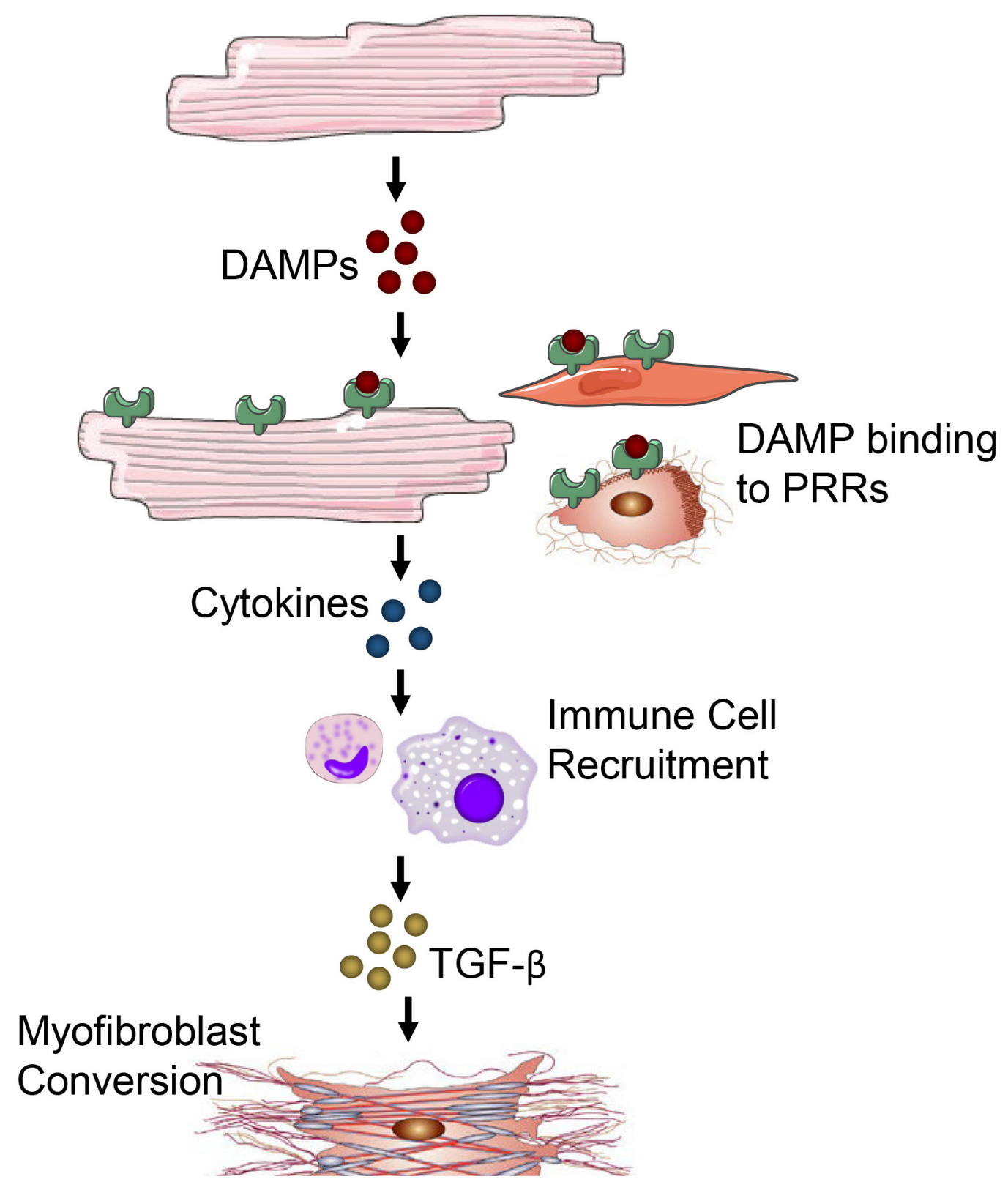

FIGURE 3 | Damage or death of cardiomyocytes leads to the release of DAMPs. DAMPs acting through PRRs on neighboring cardiomyocytes, fibroblasts, resident immune cells, endothelial cells and other parenchymal cells of the heart promote cytokine and chemokine release. Immune cells migrate in response to cytokine/chemokines in the heart and secrete TGF- $\beta$ and other pro-fibrotic factors to promote fibrosis and myofibroblast conversion.

regulate expression of matrix-degrading proteases (Li et al., 2002; Siwik and Colucci, 2004). However, the contribution of cardiac fibroblasts in activating inflammatory cascades in pathological settings is less understood. In vivo studies have been limited due to the absence of specific markers for cardiac fibroblasts (Kong et al., 2013). As a result, studies have been largely descriptive. However, infarction models in mice show activation of the inflammasome in cardiac fibroblasts, an indication of the generation of active IL-1 $\beta$ (Kawaguchi et al., 2011; Sandanger et al., 2013).

Endothelial and resident mast cell populations have also been implicated in triggering the inflammatory cascade postinfarction (Lakshminarayanan et al., 1997, 2001; Frangogiannis et al., 1998a). As previously mentioned, there is a small population of resident mast cells that plays an important role in homeostasis in the normal myocardium and during 
pathological events. Expansion of the mast cell population is associated with cardiac fibrosis in response to multiple pathological challenges (Frangogiannis et al., 1998b; Patella et al., 1998; Shiota et al., 2003; Wei et al., 2003). The mechanisms associated with this expansion is not well understood. Stem cell factor (SCF), which is known to be involved in the recruitment and differentiation of mast cell progenitors, is upregulated in hearts following myocardial infarction and may contribute to the proliferation of resident mast cells (Frangogiannis et al., 1998b). However, other studies suggest mast cell progenitors infiltrate the myocardium from outside sources (Bujak et al., 2008). Regardless of origin, mast cells are known to be vital in the pathogenesis of cardiac fibrosis. Mast cell deficiency results in attenuated perivascular fibrosis and reduced progression to decompensated heart failure in a mouse model of pressure overload (Hara et al., 2002). Pharmacological prevention mast cell product release in spontaneously hypertensive rats reduced fibrosis, reduced inflammatory cell recruitment and decreased pro-inflammatory cytokines (Levick et al., 2009).

How mast cells influence fibrosis is also poorly understood. Mast cells are known to have abundant numbers of granules that store a wide range of mediators. This includes many profibrotic mediators including TNF- $\alpha$ (Frangogiannis et al., 1998a), TGF- $\beta$ (Shiota et al., 2003), and platelet-derived growth factor (PDGF) (Nazari et al., 2016). However, these mediators are produced by many cell types and the relative contribution of mast cells has not been fully elucidated. Additionally, mast cells have abundant expression of chymase, a protease implemented in the angiotensin converting enzyme (ACE)-independent generation of angiotensin II (Urata et al., 1990a,b). This mechanism may represent an important mechanism in the progression of cardiac fibrosis in the presence of ACE inhibition.

The cytokine rich environment present in the heart following injury causes infiltration of pro-inflammatory immune cell populations including phagocytic neutrophils and mononuclear cells which clear the area of dead cells and ECM debris (Prabhu and Frangogiannis, 2016). These responses are facilitated by changes in the vasculature. Hypoxia compromises the vascular endothelial cell integrity and barrier function, increasing vessel permeability to facilitate leukocyte infiltration (Sansbury and Spite, 2016). Neutrophils are among the first immune cell types to infiltrate into the damaged heart in response to a number of pro-inflammatory mediators including DAMPs, cytokines, chemokines, endogenous lipid mediators (prostaglandins and leukotrienes), histamine and complement components (Yan et al., 2013; Puhl and Steffens, 2019). Neutrophils are continually produced from hematopoietic progenitors in the bone marrow through the process of granulopoiesis. They reside in specific niches in the bone marrow through the action of CXCL12 (Katayama et al., 2006; Russell et al., 2011). Maturation of immature neutrophils is regulated by granulocyte colonystimulating factor (G-CSF), which is produced in response to IL-17 from $\gamma \delta$ T-cells and counteracted by IL-23 (Stark et al., 2005; Liao et al., 2012; Yan et al., 2012; Savvatis et al., 2014). In this way $\gamma \delta \mathrm{T}$-cells regulate neutrophil and macrophage infiltration and have detrimental effects on remodeling in myocardial infarction models (Yan et al., 2012). Following maturation, neutrophils remain in the bone marrow through the actions of CXCR4 or are release into the circulation by CXCR2-dependent signaling (Tarzami et al., 2003; Devi et al., 2013).

Extravasation of neutrophils into the heart is dependent on adhesion interactions between the neutrophils and endothelial cells. Endothelial cells activated by PRR-dependent mechanism rapidly upregulate pre-stored $P$-selectin. There is a slower upregulation of E-selectin that is generated de novo (Ley et al., 2007; Petri et al., 2008). Circulating neutrophils express selectin ligands, which causes them to interact with the endothelium and roll along the endothelial layer. The two selectins have partially overlapping functions and bind P-selectin glycoprotein ligand 1 (PSGL1) leading to tethering of neutrophils and initiate rolling (Ley et al., 2007). Lymphocyte function-associated antigen 1 (LFA1), which binds to intracellular adhesion molecule (ICAM) 1 and 2 on endothelium facilitates neutrophil rolling (Zarbock et al., 2011). Rolling neutrophils respond to chemokines bound to the endothelial surface to induce a conformational change of integrins and endothelial cell surface molecules such as ICAM1 and ICAM2, enhancing their adhesion and resulting in arrest (Detmers et al., 1990; Herter and Zarbock, 2013). It is thought that full activation requires a two-step process initiated by specific priming pro-inflammatory cytokines including TNF $\alpha$ and IL-1 $\beta$ however other chemoattractants and growth factors may also be involved (Summers et al., 2010). This priming is also important for maximal neutrophil degranulation and activation (Guthrie et al., 1984; Summers et al., 2010). Signaling initiated by CXCL8 in humans (CXCL1, CXCL2 and CXCL5 in mice) via CXCR2 further activates neutrophils and promotes their adhesion (Pruenster et al., 2009; Williams et al., 2011). The neutrophils transmigrate through the endothelial junctions and then the basement membrane through multiple effectors including VCAM1, PECAM1, and VLA4 (Wang et al., 2006). Many of these processes have been studied extensively in other tissues and are believed to be directly applicable to the heart, however, a careful examination of cardiac specific neutrophil extravasation and transmigration process have not been extensively investigated.

Once in the tissue, neutrophils release proteolytic enzymes such as myeloperoxidase (MPO) and play an important role in clearing the area of dead cells and matrix debris (Puhl and Steffens, 2019). They may also amplify the immune response through production of pro-inflammatory mediators (Boufenzer et al., 2015) and have been shown to regulate recruitment of pro-inflammatory monocyte populations to the heart (Alard et al., 2015). While these actions are critical for proper healing, neutrophils may also exert cytotoxic actions on cardiomyocytes to exacerbate the injury (Simpson et al., 1988; Entman et al., 1992; Ali et al., 2016). These cytotoxic effects occur through the release of reactive oxygen species (ROS) and also release of granules associated with adverse left ventricular remodeling (Vasilyev et al., 2005; Ciz et al., 2012).

Following injury, this resident macrophage populations expands (Yan et al., 2013). There are two distinct subsets of monocyte recruitment to the damaged heart (Nahrendorf et al., 2007). Pro-inflammatory, M1-like macrophages are recruited to the heart shortly after neutrophils. This initial population of 
macrophages is derived from bone marrow progenitor cells and release from splenic reservoirs. They are recruited to the heart through the MCP-1(CCL2)/CCR2 axis (Swirski et al., 2009; Bajpai et al., 2018). The first subset is pro-inflammatory and recruited through the MCP-1(CCL2)/CCR2 axis. This pro-inflammatory population is characterized by high Ly-6C expression (Dewald et al., 2005). Infiltrating Ly-6C ${ }^{\text {high }}$ populations are derived from bone marrow progenitor cells and reservoirs of mononuclear cells in the spleen that can be deployed quickly to the site of inflammation (Swirski et al., 2009). These M1-like macrophages are proteolytic with increased expression of proteinases such as cathepsins and MMPs and are involved in ECM remodeling due to being a major source of MMPs and TIMPs (Huang et al., 2012; Khokha et al., 2013). Like fibroblasts, macrophages play a role in ECM remodeling through the secretion of ECM components. These classically activated macrophage populations serve as a major source of pro-inflammatory cytokines including IL-12, IL-23, IL-1, and IL-6 as well as being involved in phagocytosis.

\section{THE PROLIFERATIVE PHASE}

Suppression and resolution of inflammation is an active process. While the mechanisms contributing to the initiation of inflammation have been well characterized, resolution of inflammation is not as well understood. Neutrophils that are recruited initially during the inflammatory phase are shortlived cells and rapidly undergo cell death primarily through apoptosis, but also necrosis, which releases mediators that promote the resolution of inflammation including lipoxins and resolvins that suppress neutrophil transmigration and promote neutrophil apoptosis (Serhan et al., 2008; Mantovani et al., 2011; Geering et al., 2013). Dying neutrophils also express decoy and scavenging receptors that deplete the area of inflammatory mediators (Soehnlein and Lindbom, 2010; Penberthy and Ravichandran, 2016). Phagocytosis of necrotic neutrophils by macrophages clears the area of apoptotic cells and induces a pro-resolving M2 macrophage phenotype characterized by the secretion of suppressors of inflammation such as transforming growth factor (TGF)- $\beta$, IL-10, interleukin receptor associated kinase-M (Chen et al., 2012) and pro-resolving lipid mediators such as lipoxins and resolvins (Sansbury and Spite, 2016; Horckmans et al., 2017). An anti-inflammatory/reparative monocyte subpopulation is recruited to contribute to the M2like macrophage pool and contributes to the resolution of inflammatory responses. Similarly, these pro-resolving, M2-like macrophages secrete anti-inflammatory, pro-fibrotic and proangiogenic cytokines including IL-10 and TGF- $\beta$ to suppress inflammation and promote tissue repair.

Dendritic cells infiltrate the damaged heart predominantly during the reparative phase (Yan et al., 2013). They play an important role in the resolution of inflammation, scar formation and angiogenesis. Deletion of dendritic cells prolongs the accumulation of Ly- $6 \mathrm{C}^{\text {high }}$ monocytes, pro-inflammatory macrophages and pro-inflammatory mediators (Anzai et al., 2012). Mice lacking dendritic cells have a reduction in endothelial cell proliferation and worsened cardiac function following myocardial infarction. Additionally, they have been shown to play a role in activation of $\mathrm{T}$ cell populations, which play a role in remodeling (Van der Borght et al., 2017). They also play an important role in phagocytosis of foreign or damaged material and antigen presentation making them an important link between the innate and adaptive immune response (Dieterlen et al., 2016; Van der Borght et al., 2017).

Lymphocytes migrate to the heart following injury and there is emerging evidence for an important role of lymphocyte populations in mediating cardiac fibrosis in both ischemic and non-ischemic heart failure (Laroumanie et al., 2014; Nevers et al., 2015; Bansal et al., 2017). The cause of $\mathrm{T}$ lymphocytes in the non-ischemic myocardium is uncertain but may be a result of mechanical-stress activation of neurohumoral pathways (Amador et al., 2014; Li et al., 2017). In the ischemic heart, $\mathrm{T}$ cells are recruited via chemokine-dependent mechanisms primarily during the reparative phase (Dobaczewski et al., 2010b). Cytotoxic T cells are activated after infarction and may exert cytotoxic actions on healthy cardiomyocytes in a mechanism that is thought to involve cross-reactive cardiac antigens (Varda-Bloom et al., 2000; Ilatovskaya et al., 2019). B cells are also recruited to the heart through poorly understood mechanisms (Wang et al., 2019). They are thought to have a negative impact on remodeling though their role is not well defined (Adamo et al., 2018, 2020). B cells promote mobilization of pro-inflammatory Ly- $6 \mathrm{C}^{\text {high }}$ monocytes through the production of CCL7 and may affect the heart through their role in antibody deposition (Zouggari et al., 2013; Adamo et al., 2020). CD4+ helper T cells play an important role in response to cardiac injury. Following myocardial infarction, they are likely activated by cardiac autoantigens to promote wound healing, resolution of inflammation, proper collagen matrix and scar formation (Hofmann et al., 2012). Studies using CD4+ T-cell deficient mice, mice lacking the MHCII genes and OT-II mice that have defective T-cell antigen recognition, have augmented infiltrating leukocytes and disrupted collagen matrix formation Hofmann et al., 2012). Regulatory T cells $(\mathrm{CD} 4+$ Foxp3+) are also critical for favorable wound healing, scar formation and resolution of inflammation after myocardial infarction, in part, through modulating macrophage polarization toward an M2-like phenotype (Weirather et al., 2014). NKT cell activation reduces leukocyte infiltration and adverse remodeling following both non-perfused and reperfused myocardial infarction partially through enhanced expression of IL-10 and other anti-inflammatory cytokines (Sobirin et al., 2012; Homma et al., 2013).

Along with the repression of inflammation, there is induction of mediators that activate mesenchymal cells. During the proliferative phase there is abundant infiltration of fibroblasts and vascular cells. Suppression of pro-inflammatory signaling such as IL- $1 \beta$ and interferon- $\gamma$-inducible protein (IP)-10 allows for growth and infiltration of cardiac fibroblasts (Palmer et al., 1995; Koudssi et al., 1998). Fibroblast migration is a critical aspect of fibroblast biology in the damaged myocardium. Fibroblasts must migrate to the site of dead cardiomyocytes for optimal repair in a manner that is dependent on their ability to degrade and deposit matrix (Tschumperlin, 2013). Several factors have been 
shown to mediate fibroblast migration including leukotrienes (Blomer et al., 2013), cytokines such as IL-1 $\beta$ and cardiotrophin1 (Mitchell et al., 2007; Freed et al., 2011) and growth factors including fibroblast growth factor (FGF) and TGF- $\beta$ (Detillieux et al., 2003; Liu et al., 2008).

Fibroblast proliferation also plays an important role during the proliferative phase. Studies demonstrate an intense proliferation of fibroblasts in the injured heart (Frangogiannis et al., 1998b; Virag and Murry, 2003). Many factors influence fibroblast proliferation including the growth factors fibroblast growth factor (FGF)-2 and platelet-derived growth factor (PDGF) (Booz and Baker, 1995; Zymek et al., 2006). Other factors including angiotensin II, mast cell-derived tryptase and chymase also play a role. However, the relative importance of these factors is not well defined.

Following infiltration and proliferation at the sight of injury, fibroblasts differentiate into myofibroblast. Myofibroblasts arise primarily through proliferation of resident fibroblasts (Fredj et al., 2005; Teekakirikul et al., 2010; Ali et al., 2014; Moore-Morris et al., 2014) and are characterized by the expression of contractile proteins and the ability to secrete large amounts of matrix proteins (Cleutjens et al., 1995b). While myofibroblasts may become activated through several potential mechanisms, transforming growth factor (TGF)- $\beta$ is the best characterized mechanism of myofibroblast activation. TGF- $\beta$ is upregulated in the damaged heart and induces transcription of myofibroblast genes through canonical Smaddependent signaling (Dobaczewski et al., 2010a). Alternatively, non-canonical signaling through p38 mitogen-activated protein kinase (MAPK), also plays a role in myofibroblast conversion (Hashimoto et al., 2001; Sousa et al., 2007).

Activated myofibroblasts secrete ECM to form the fibrotic scar. Myofibroblasts are thought to represent the main source of ECM deposition (Cleutjens et al., 1995a; Squires et al., 2005). Secretion of structural proteins including collagens and fibronectin as well as matrix metabolism through the expression of MMPs and TIMPs are critical for fibrosis. At the end of the proliferative phase, there is an ECM composed primarily of collagen. Signals leading to the transition from the proliferative to the maturation phase are not well characterized. Regardless, fibrotic and angiogenic responses are halted, preventing the expansion of fibrosis and leading to the maturation phase.

\section{THE MATURATION PHASE}

The maturation phase follows the proliferative phase and is characterized by mature scar formation. During the maturation phase, cross-linking of the extra cellular matrix occurs. Reparative cells that are present during the proliferative phase become deactivated and may go through apoptosis. The mechanisms involved in the transition from the proliferative phase to the maturation phase are largely unknown. Myofibroblasts undergo quiescence, potentially due to a lessening of fibrotic growth factors and decreased TGF- $\beta$ and angiotensin II signaling. They may also go through apoptotic death (Takemura et al., 1998).

\section{INFLAMMATION IN MYOCARDITIS}

Inflammatory cardiomyopathy or myocarditis occurs due to inflammation in the heart. Unlike other forms of heart failure, myocarditis is initiated by a pathogen or autoimmune response and may produce a unique type of inflammation depending on the causative agent. Myocarditis is commonly associated with viral infection (Caforio et al., 2007), the Coxsackie virus of group B (CVB) is the most studied, which leads to viral particle processing by innate immune cells followed by antigen presentation and activation of the antiviral cytotoxic CD8+ $\mathrm{T}$ cells and some CD4+ $\mathrm{T}$ cell populations. While viruses of the adenovirus, enterovirus, and parvovirus families are most commonly associated with myocarditis, other infectious events including bacterial causes such as staphylococcus, streptococcus and Clostridia infections, fungal diseases including aspergillosis and actinomycosis, protozoan illnesses such as Chagas disease and malaria and parasitic infections like in schistosomiasis. Toxins and autoimmune disorders can also give rise to myocarditis (Caforio et al., 2007). While the immune response is unique depending on the cause of myocarditis, common hallmarks include inflammatory cell infiltration, which can lead to fibrosis. Inflammation in myocarditis is highly linked to the severity of the disease (Kindermann et al., 2008). Most individuals who have inflammatory cardiomyopathy see a resolution of symptoms however, the type, extent and duration of the inflammatory response determines whether myocarditis will be resolved or progress to dilated cardiomyopathy and ultimately heart failure. Patients with an acute hypersensitive myocarditis seem to recover after a few days, while patients with giant cell myocarditis and eosinophilia myocarditis more often progress to heart failure (Fung et al., 2016).

Similar to other forms of injury, the noxious insult initiating myocarditis causes damage to cardiomyocytes, stimulating the recruitment of circulating immune cells. If the extent of damage results in a loss of cardiomyocytes, the heart repairs itself through the deposition of ECM and myocardial fibrosis. This process can be exacerbated by continued inflammation due to prolonged exposure to the pathogen or toxic agent, $\mathrm{T}$ lymphocyte responses to specific antigens and persistent immune responses due to antibodies against or similar to endogenous heart antigens (Cooper, 2009).

\section{INFLAMMATION IN HYPERTENSION}

Hypertension involves both the innate and adaptive immune system throughout the progression of the disease. Inflammation is believed to be a contributing factor to the diseased state of hypertension. $\mathrm{T}$ lymphocytes have been shown to have a role in the onset of the disease in an Angiotensin II (Ang II)-induced hypertension mouse model. In a RAG-1 ${ }^{-/}$mouse model null of $\mathrm{T}$ and $\mathrm{B}$ lymphocytes, mice display a dampened form of hypertension, while reintroduction of $\mathrm{T}$ cells recapitulated the classical hypertension readouts (Guzik et al., 2007). A more recent study closely investigated the role of $\mathrm{B}$ lymphocytes in Ang II-induced hypertension and found depletion of B cells 
ablated the phenotype associated with the model and adoptive transfer of $\mathrm{B}$ cells recapitulated the hypertensive phenotype (Chan et al., 2015). In a similar Ang II infusion induced hypertensive mouse model, immune cells of the monocytic lineage were shown to be a key mediator in enabling vascular dysfunction (Wenzel et al., 2011; Harrison, 2014). Ablation of LysM+ monocytes in this model significantly dampened vascular macrophage infiltration, aortic macrophage populations, and inflammatory gene expression in vasculature. The common accepted mechanism follows enhancement of hypertension symptoms due to the stress put on vasculature and the release of damage associated molecular patterns (DAMPs) causing a secondary chronic inflamed state (Drummond et al., 2019). The involvement of the immune system in hypertension further exacerbates the disease state induced by high blood pressure.

\section{CYTOKINES-MEDIATORS OF FIBROSIS}

Many of the Th-2 cytokines were first recognized as having pro-fibrotic properties including IL-4, IL-5, IL-10, and IL-13. IL-4 has been shown to increase collagen and matrix protein synthesis in fibroblasts (Fertin et al., 1991; Postlethwaite et al., 1992) and deletion reduces myocardial fibrosis (Kanellakis et al., 2012; Peng et al., 2015). IL-4 is pleiotropic in nature and effects a variety of cell types including having immunosuppressive effects on pro-inflammatory mediators (Hart et al., 1989; Levings and Schrader, 1999). IL-13 has also been shown to directly activate fibroblasts (Oriente et al., 2000) and plays a role in fibrosis and deletion in mice aggravates healing after myocardial infarction (Hofmann et al., 2014).

While many immune responses are thought to be a reciprocal regulation between cell populations, Th-1 and Th-17 cytokines also promote fibrogenesis (Mosmann and Coffman, 1989; Choy et al., 2015). IL-17 has reported direct and indirect pro-fibrotic properties (Li et al., 2014). Some Th1 cytokines, including TNF- $\alpha$, are pro-fibrotic while others, such as IFN- $\gamma$ and IL-12, are antifibrotic (Zhang et al., 2011; Han et al., 2012; Li et al., 2012; Kimura et al., 2018; Lee et al., 2019).

\section{INTERLEUKIN-1}

IL- $1 \alpha$ and IL- $1 \beta$ are upregulated in the injured heart and play an important role in inducing the expression of other cytokines, chemokines, adhesion molecules and growth factors (Guillen et al., 1995; Herskowitz et al., 1995). Most cell types in the heart are impacted by IL- 1 family members, particularly IL- $1 \beta$. It plays a large role in pro-inflammatory leukocyte recruitment to the heart following damage (Saxena et al., 2013). Notably, IL-1 $\beta$ has been found to be particularly important in regulating cardiac fibroblast function during the inflammatory phase. It is markedly upregulated in the infarcted myocardium (Herskowitz et al., 1995; Christia et al., 2013). Induction mediates inflammatory signaling and ECM metabolism through its effects on proteases (Bujak et al., 2008). IL-1 $\beta$ promotes fibroblast migration through increasing the expression of proteins involved in ECM turnover
(Mitchell et al., 2007). IL-1 $\beta$ may also play a role in the conversion of fibroblasts into myofibroblasts (Saxena et al., 2013). It has also been linked to fibroblast proliferation where it has been shown to inhibit proliferation through the modulation of cyclins, cyclin-dependent kinases and their inhibitors (Palmer et al., 1995; Koudssi et al., 1998). However, many of these studies were performed in vitro and the actions of IL- $1 \beta$ in vivo is less clear.

In vivo studies assessing the role of $\mathrm{IL}-1 \beta$ are more confounding. Viral overexpression of IL-1 receptor antagonist (IL-1ra) in the hearts of rats subjected to ischemia reperfusion injury was protective through the inhibition of inflammatory responses and decreased cardiomyocyte apoptosis (Suzuki et al., 2001). Global IL-1RI knockout mice have decreased inflammation and immune cell recruitment following myocardial infarction, which culminated in an attenuated fibrotic response (Bujak et al., 2008). Contrarily, neutralizing antibody administration for IL-1 $\beta$ in mice in the acute phase after myocardial infarction delayed the wound healing process leading to increased incidence of cardiac rupture and enhanced maladaptive remodeling long-term (Hwang et al., 2001). These confounding studies demonstrate the increasingly appreciated pleiotropic nature of many cytokines including the IL-1 family.

\section{INTERLEUKIN-6}

IL-6 has been extensively characterized for its role in increasing fibroblast proliferation and myocardial fibrosis (Banerjee et al., 2009). It is a member of a family of structurally related cytokines including oncostatin- $\mathrm{M}$ and cartotrophin-1 that have overlapping functions. IL-6 effects most cells of the heart. In cardiomyocytes, IL- 6 protects cells from death and promotes hypertrophy (Sano et al., 2000; Smart et al., 2006). Inhibition of IL-6 diminishes acute immune cell recruitment (Muller et al., 2014). Lack of IL-6 protects the heart from fibrosis in several models of heart failure (Gonzalez et al., 2015; Zhang et al., 2016).

\section{INTERLEUKIN-10}

IL-10 is upregulated in the injured heart (Frangogiannis et al., 2000a). It is produced primarily by activated Th2 cells and monocytes that have anti-inflammatory properties (Frangogiannis et al., 2000a). In macrophages, IL-10 suppresses the synthesis of pro-inflammatory cytokines and chemokines such as IL-1, IL-6, and TNF- $\alpha$ (Fiorentino et al., 1991). It can also regulate ECM remodeling through the regulation of MMPs and TIMPs (Lacraz et al., 1995). IL-10 knockout mice have increased mortality and enhanced inflammation in response to ischemia/reperfusion injury (Yang et al., 2000). Since IL-10 is increased at later time points following myocardial infarction and has potent anti-inflammatory effects, it would be anticipated that IL-10 might play an important role in the resolution of inflammation. However, studies have been conflicting. Studies using IL-10 knockout mice showed that, while mice have augmented acute inflammatory responses, resolution of inflammation was unchanged (Zymek et al., 2007). 


\section{TUMOR-NECROSIS FACTOR}

TNF- $\alpha$ is a pleiotropic cytokine capable of effecting all cell types involved in cardiac injury and repair. It is able to suppress cardiac contractility and augment cardiomyocyte apoptosis (Finkel et al., 1992; Yokoyama et al., 1993). Secretion by various cell types involved in remodeling enhances production of proinflammatory cytokines, chemokines and adhesion molecules by immune cells. TNF- $\alpha$ can also effect ECM metabolism through its ability to decreased collagen synthesis in fibroblasts and enhance MMP activity (Siwik et al., 2000). While these findings and studies showing that TNF- $\alpha$ knockout mice have decreased inflammation and improvements in cardiac remodeling and function following myocardial infarction suggest TNF- $\alpha$ neutralization would be beneficial in the injured heart, this has not been the case (Maekawa et al., 2002; Berthonneche et al., 2004; Sugano et al., 2004; Sun et al., 2004). Inhibiting TNF- $\alpha$ through gene therapy to express the soluble TNF receptor produced deleterious effects in a mouse model of myocardial infarction through increased incidence of cardiac rupture and augmented cardiac remodeling (Monden et al., 2007b). Genetic deletion of TNFR1/TNFR2 produced increased infarct size and enhanced cardiomyocyte apoptosis following myocardial infarction (Kurrelmeyer et al., 2000). These findings have been proposed to be due to distinct TNF- $\alpha$ effects through different receptor subtypes (Monden et al., 2007a), but may also be attributed to the complex nature of TNF- $\alpha$ signaling on biological processes in the heart.

\section{INTERFERONS}

Interferons (IFN) can be secreted by immune cells or fibroblasts to effect a wide array of biological responses (Noppert et al., 2007; Ivashkiv and Donlin, 2014). IFN- $\gamma$ knockout mice have a reduction in the myofibroblast marker $\alpha$-smooth muscle actin following angiotensin II administration (Han et al., 2012). Similarly, mice lacking the INF- $\gamma$ receptor have decreased cardiac hypertrophy and fibrosis along with reductions in macrophage and $\mathrm{T}$ cell infiltration following angiotensin II infusion (Marko et al., 2012). However, these studies used global knockout mice and fail to determine the specific cardiac contribution of immune cells compared to fibroblasts.

\section{TRANSFORMING GROWTH FACTOR FAMILY}

TGF- $\beta 1$ has been proposed to be a master regulator in the transition from inflammation to repair in the damaged heart (Dobaczewski et al., 2011). Neutralization of TGF$\beta 1$ worsens cardiac dysfunction and prolongs inflammation in a model of myocardial infarction (Ikeuchi et al., 2004). However, cardiomyocyte-specific knockout of TGF- $\beta$ receptors is protective and promotes anti-inflammatory and cytoprotective signaling (Rainer et al., 2014). These studies suggest that the detrimental effects of loss of TGF- $\beta 1$ signaling is not likely through directly impacting cardiomyocytes, but though loss of anti-inflammatory actions and fibrosis. In addition to its role in suppressing inflammation and promoting reparative immune responses, TGF- $\beta 1$ is critical for myofibroblast transdifferentiation (Hashimoto et al., 2001; Wang et al., 2005; Dobaczewski et al., 2010a).

Growth differentiation factor-15 (GDF-15) is also a member of the TGF- $\beta$ family that has been implicated in suppression of inflammation after myocardial infarction. GDF-15 counteracts integrin activation on leukocytes to curb pro-inflammatory responses (Kempf et al., 2011). Knockout of GDF-15 in mice augments inflammation and increases cardiac rupture following myocardial infarction (Kempf et al., 2011). This is also reflected in the patient population where patients with elevated plasma GDF-15 are prone to increased mortality (Kempf et al., 2007).

\section{CLINICAL PERSPECTIVES}

Currently approved heart failure therapies target the short-term clinical status to minimize symptoms and improve quality of life, but long-term prognosis remains poor (Machaj et al., 2019). Treatments aimed at preventing the progression of heart failure or reversing maladaptive remodeling are an attractive target, but have culminated in minimal success. Due to the involvement of inflammation in all stages of disease progression, targeting the immune response has been an ongoing area of interest to address this unmet clinical need. In the past two decades the field of cardiac inflammation has made numerous ventures into clinical trials targeting inflammatory pathways. To date, cytokine-targeted therapies have dominated with clinical trials targeting TNF- $\alpha$ and IL-1 $\beta$ (Murphy et al., 2020).

Early studies identified TNF- $\alpha$ as a potential therapeutic target due to its known role as a pro-inflammatory mediator in heart failure. To date, several randomized, placebo-controlled, anti-TNF- $\alpha$ studies have been performed. The RENEWAL trial (Randomized Etanercept Worldwide Evaluation), testing etanercept, and the ATTACH trial (Anti-TNF- $\alpha$ Therapy Against Congestive Heart Failure), involving infliximab, showed no indication of beneficial effects with treatment and the ATTACH trial exposed adverse effects of anti-TNF- $\alpha$ therapy (Bozkurt et al., 2001; Chung et al., 2003; Mann et al., 2004). These initial studies targeting the inflammatory response demonstrate our lack of understanding and under appreciation of the complexity of immune system involvement in heart failure. TNF$\alpha$ is a widely expressed cytokine with pleotropic actions. This includes a protective role in cardiomyocytes by preventing death (Kurrelmeyer et al., 2000; Evans et al., 2018). Appropriate TNF- $\alpha$ levels may also be necessary for adequate tissue remodeling and repair (Anker and Coats, 2002).

IL- $1 \beta$ is another potential cytokine target for the treatment of heart failure due to its up-regulation in heart failure, role in pro-inflammatory responses and positive benefits from IL$1 \beta$ inhibition in preclinical trials (Van Tassell et al., 2015). The CANTOS trial (Canakinumab Anti-Inflammatory Thrombosis Outcome Study) was a randomized, double-blinded, placebocontrolled, anti-IL-1 $\beta$ study investigating the use of the 


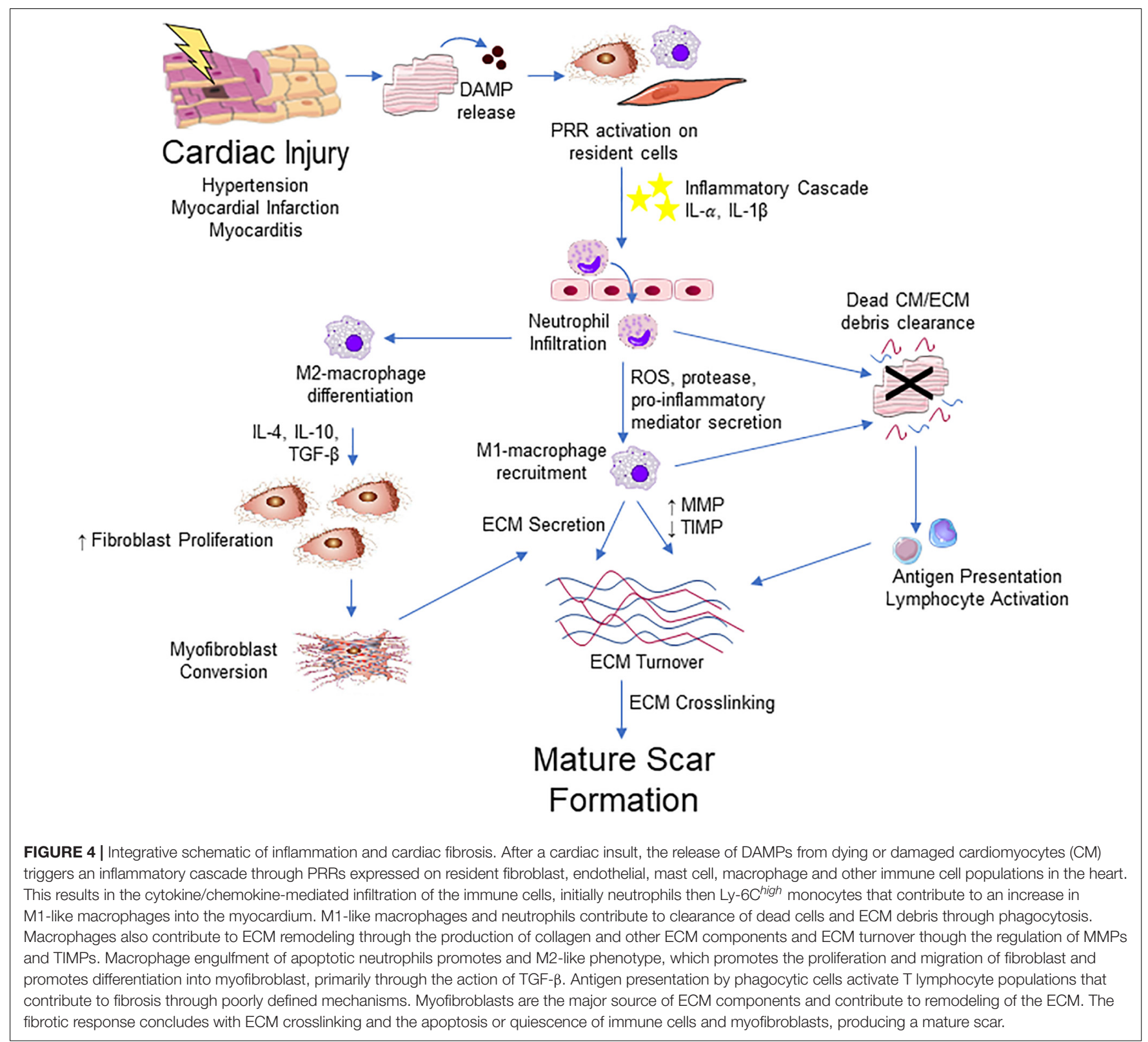

monoclonal antibody canakinumab (Ridker et al., 2017). All doses tested had a positive impact on inflammatory burden as indicated by C-reactive protein. However, only the highest dose examined $(150 \mathrm{mg}$ ) was successful in reducing one of the primary end points of the study, reoccurrence of non-fatal MI, with no changes in other end points including stroke or cardiovascular death.

The ACCLAIM trial (Advanced Chronic Heart Failure Clinical Assessment of Immune Modulation Therapy) was a double-blinded, placebo-controlled study using a device-based non-specific immunomodulation therapy approach (TorreAmione et al., 2008). This study did not find a significant reduction in cardiovascular hospitalization or mortality. However, in certain populations, those without a previous myocardial infarction and New York Heart Association (NYHA)
II heart failure, significant reductions in primary endpoints were observed, suggesting that this approach may be beneficial in certain groups. Important to note, the mechanisms of immunomodulation are not well defined and the impact on cytokine levels were not measured making the findings difficult to interpret at a mechanistic level.

The clinical trials targeting inflammation for the treatment of heart failure, with the exception of the CANTOS trial (anti-IL$1 \beta$ ), have been largely disappointing (Van Tassell et al., 2015). However, to date, strategies have broadly targeted inflammation through either a generic approach or inhibition of cytokines that have an array of functions on many cell types. It is also important to note that these studies involve subsets of heart failure patients and it should not be discounted that these approaches may be valuable in certain patient populations such as inflammatory 
cardiomyopathies. These findings highlight our need for a better understanding of how inflammation contributes to the pathogenesis of heart failure. More recent preclinicial studies targeting a specific signaling pathways and cell populations give hope for future immunomodulatory therapies for the treatment of heart failure. The CCL2/CCR2 axis that is important for infiltrating pro-inflammatory monocytes has be targeting using small molecular antagonists (Hilgendorf et al., 2014; Grisanti et al., 2016; Liao et al., 2018; Patel et al., 2018), antibodies (Patel et al., 2018), small interfering RNA (Leuschner et al., 2011), lipid micelles containing CCR2 antagonists (Wang et al., 2018), and microparticles (Getts et al., 2014). Antibody-depletion based approaches targeting lymphocyte populations including CD3 and CD4 antibodies for T cell (Nevers et al., 2015; Bansal et al., 2017), CD25 for regulatory $T$ cell (Bansal et al., 2019) and CD22 for B cell (Cordero-Reyes et al., 2016) depletion all display promise. However, if these and other preclinical studies translate in humans remains to be seen.

\section{THE IMPACT OF INFLAMMATION ON FIBROSIS}

It should be apparent that inflammation is a major regulator of the reparative response after cardiac injury (Figure 4). Inflammatory cells, such as neutrophils and macrophages, infiltrate to the site of injury where they release numerous pro-inflammatory mediators including tumor necrosis factor (TNF)- $\alpha$, interleukin (IL)-1 $\beta$ and IL-6. These cytokines play an important role in the induction of resident fibroblast proliferation and activation of myofibroblasts initiating the production of ECM components (Christia et al., 2013). In turn, activated cardiac fibroblasts upregulate various cytokine and growth factors to influence healing via autocrine and paracrine-dependent mechanisms (Zhao and Eghbali-Webb, 2001).

Monocytes/macrophages play an important role in the fibrotic response following injury. While it is now recognized that the historical view of macrophage polarization into M1 and M2 phenotypes is an oversimplification and there are several differentiation states that are dynamic in response to changes in the environmental milieu (Xue et al., 2014), these distinct populations play unique roles in their modulation of fibrosis. Macrophage-derived TGF- $\beta$ induces migration, growth and activation of fibroblasts and promotes collagen synthesis (Fine and Goldstein, 1987; Clark et al., 1997; Acharya et al., 2008). Macrophages also represent an important source of MMPs and

\section{REFERENCES}

Abe, R., Donnelly, S. C., Peng, T., Bucala, R., and Metz, C. N. (2001). Peripheral blood fibrocytes: differentiation pathway and migration to wound sites. J. Immunol. 166, 7556-7562. doi: 10.4049/jimmunol.166.12.7556

Acharya, P. S., Majumdar, S., Jacob, M., Hayden, J., Mrass, P., Weninger, W., et al. (2008). Fibroblast migration is mediated by CD44-dependent TGF beta activation. J. Cell Sci. 121(Pt 9), 1393-1402. doi: 10.1242/jcs.021683

Adamo, L., Rocha-Resende, C., and Mann, D. L. (2020). The emerging role of b lymphocytes in cardiovascular disease. Annu. Rev. Immunol. 38, 99-121. doi: 10.1146/annurev-immunol-042617-053104
TIMPs that influence matrix degradation (Huang et al., 2012; Khokha et al., 2013). MMPs are also involved in the control of chemokines to influence inflammatory responses (Van den Steen et al., 2000; Dean et al., 2008; Song et al., 2013).

During the proliferative phase of cardiac repair, cardiac fibroblast populations undergo expansion and conversion to myofibroblasts (Travers et al., 2016). The conversion of macrophages to a reparative phenotype promotes the recruitment and expansion of fibroblasts through the secretion of pro-fibrotic factors (Bajpai et al., 2018). These macrophages and recruited lymphocyte populations contribute to the activation of fibroblasts into a myofibroblast phenotype through cytokine release of factors such as TGF- $\beta$ (Dobaczewski et al., 2011). Myofibroblasts, in turn, generate large amounts of ECM to repair the damaged heart (Travers et al., 2016).

The interplay between the immune and fibrotic response is extremely interconnected. Immune cells regulate all aspects of fibroblast biology and fibroblasts, in turn, regulate immune cell recruitment, activation and function. Dissecting the role of the various mediators has proven to be difficult due to the pleiotropic nature of many of these factors and their context-dependent and cell type-dependent nature. Furthermore, lack of cell type specific markers has hampered progress. Understanding the relationship between inflammation and cardiac remodeling is an important avenue of study due to its importance for recovery and represent a significant potential area of therapeutic intervention.

\section{AUTHOR CONTRIBUTIONS}

TT and LG designed the topic, collected the references, wrote the text, and revised the manuscript. Both authors contributed to the article and approved the submitted version.

\section{FUNDING}

This work was supported by an American Heart Association Scientific Development Grant 17SDG33400114 (LG).

\section{ACKNOWLEDGMENTS}

Figures were created using Servier Medical Art templates, and are licensed under Creative Commons Attribution 3.0 Uniported License (https://smart.servier.com). et al. (2018). Modulation of subsets of cardiac B lymphocytes improves cardiac function after acute injury. JCI Insight. 3:e120137.

Akira, S., and Takeda, K. (2004). Toll-like receptor signalling. Nat. Rev. Immunol. 4, 499-511.

Alard, J. E., Ortega-Gomez, A., Wichapong, K., Bongiovanni, D., Horckmans, M., Megens, R. T., et al. (2015). Recruitment of classical monocytes can be inhibited by disturbing heteromers of neutrophil HNP1 and platelet CCL5. Sci. Transl. Med. 7:317ra196. doi: 10.1126/scitranslmed.aad5330

Ali, M., Pulli, B., Courties, G., Tricot, B., Sebas, M., Iwamoto, Y., et al. (2016). Myeloperoxidase inhibition improves ventricular function and remodeling 
after experimental myocardial infarction. JACC Basic Transl. Sci. 1, 633-643. doi: 10.1016/j.jacbts.2016.09.004

Ali, S. R., Ranjbarvaziri, S., Talkhabi, M., Zhao, P., Subat, A., Hojjat, A., et al. (2014). Developmental heterogeneity of cardiac fibroblasts does not predict pathological proliferation and activation. Circ. Res. 115, 625-635. doi: 10.1161/ circresaha.115.303794

Amador, C. A., Barrientos, V., Pena, J., Herrada, A. A., Gonzalez, M., Valdes, S., et al. (2014). Spironolactone decreases DOCA-salt-induced organ damage by blocking the activation of $\mathrm{T}$ helper 17 and the downregulation of regulatory T lymphocytes. Hypertension 63, 797-803. doi: 10.1161/hypertensionaha.113. 02883

Anderson, K. R., Sutton, M. G., and Lie, J. T. (1979). Histopathological types of cardiac fibrosis in myocardial disease. J. Pathol. 128, 79-85. doi: 10.1002/path. 1711280205

Anker, S. D., and Coats, A. J. (2002). How to RECOVER from RENAISSANCE? The significance of the results of RECOVER, RENAISSANCE, RENEWAL and ATTACH. Int. J. Cardiol. 86, 123-130. doi: 10.1016/s0167-5273(02)00470-9

Anzai, A., Anzai, T., Nagai, S., Maekawa, Y., Naito, K., Kaneko, H., et al. (2012). Regulatory role of dendritic cells in postinfarction healing and left ventricular remodeling. Circulation 125, 1234-1245. doi: 10.1161/circulationaha.111. 052126

Bajpai, G., Schneider, C., Wong, N., Bredemeyer, A., Hulsmans, M., Nahrendorf, M., et al. (2018). The human heart contains distinct macrophage subsets with divergent origins and functions. Nat. Med. 24, 1234-1245. doi: 10.1038/s41591018-0059-x

Banerjee, I., Fuseler, J. W., Intwala, A. R., and Baudino, T. A. (2009). IL-6 loss causes ventricular dysfunction, fibrosis, reduced capillary density, and dramatically alters the cell populations of the developing and adult heart. Am. J. Physiol. Heart Circ. Physiol. 296, H1694-H1704.

Banerjee, I., Fuseler, J. W., Price, R. L., Borg, T. K., and Baudino, T. A. (2007). Determination of cell types and numbers during cardiac development in the neonatal and adult rat and mouse. Am. J. Physiol. Heart Circ. Physiol. 293, H1883-H1891.

Bansal, S. S., Ismahil, M. A., Goel, M., Patel, B., Hamid, T., Rokosh, G., et al. (2017). Activated $\mathrm{T}$ lymphocytes are essential drivers of pathological remodeling in ischemic heart failure. Circ. Heart Fail. 10:e003688.

Bansal, S. S., Ismahil, M. A., Goel, M., Zhou, G., Rokosh, G., Hamid, T., et al. (2019). Dysfunctional and proinflammatory regulatory T-Lymphocytes are essential for adverse cardiac remodeling in ischemic cardiomyopathy. Circulation 139, 206-221. doi: 10.1161/circulationaha.118.036065

Benjamin, E. J., Muntner, P., Alonso, A., Bittencourt, M. S., Callaway, C. W., Carson, A. P., et al. (2019). Heart disease and stroke statistics-2019 update: a report from the american heart association. Circulation 139, e56-e528.

Berthonneche, C., Sulpice, T., Boucher, F., Gouraud, L., de Leiris, J., O'Connor, S. E., et al. (2004). New insights into the pathological role of TNF-alpha in early cardiac dysfunction and subsequent heart failure after infarction in rats. Am. J. Physiol. Heart Circ. Physiol. 287, H340-H350.

Bliksoen, M., Mariero, L. H., Torp, M. K., Baysa, A., Ytrehus, K., Haugen, F., et al. (2016). Extracellular mtDNA activates NF-kappaB via toll-like receptor 9 and induces cell death in cardiomyocytes. Basic Res. Cardiol. 111:42.

Blomer, N., Pachel, C., Hofmann, U., Nordbeck, P., Bauer, W., Mathes, D., et al. (2013). 5-Lipoxygenase facilitates healing after myocardial infarction. Basic Res. Cardiol. 108:367.

Booz, G. W., and Baker, K. M. (1995). Molecular signalling mechanisms controlling growth and function of cardiac fibroblasts. Cardiovasc. Res. 30, 537-543. doi: 10.1016/0008-6363(96)88507-5

Boufenzer, A., Lemarie, J., Simon, T., Derive, M., Bouazza, Y., Tran, N., et al. (2015). TREM-1 mediates inflammatory injury and cardiac remodeling following myocardial infarction. Circ. Res. 116, 1772-1782. doi: 10.1161/circresaha.116. 305628

Bozkurt, B., Torre-Amione, G., Warren, M. S., Whitmore, J., Soran, O. Z., Feldman, A. M., et al. (2001). Results of targeted anti-tumor necrosis factor therapy with etanercept (ENBREL) in patients with advanced heart failure. Circulation 103, 1044-1047. doi: 10.1161/01.cir.103.8.1044

Bucala, R., Spiegel, L. A., Chesney, J., Hogan, M., and Cerami, A. (1994). Circulating fibrocytes define a new leukocyte subpopulation that mediates tissue repair. Mol. Med. 1, 71-81. doi: 10.1007/bf03403533
Bujak, M., Dobaczewski, M., Chatila, K., Mendoza, L. H., Li, N., Reddy, A., et al. (2008). Interleukin-1 receptor type I signaling critically regulates infarct healing and cardiac remodeling. Am. J. Pathol. 173, 57-67. doi: 10.2353/ajpath.2008. 070974

Burt, J. R., Zimmerman, S. L., Kamel, I. R., Halushka, M., and Bluemke, D. A. (2014). Myocardial T1 mapping: techniques and potential applications. Radiographics 34, 377-395. doi: 10.1148/rg.342125121

Caforio, A. L., Calabrese, F., Angelini, A., Tona, F., Vinci, A., Bottaro, S., et al. (2007). A prospective study of biopsy-proven myocarditis: prognostic relevance of clinical and aetiopathogenetic features at diagnosis. Eur. Heart J. 28, 13261333. doi: 10.1093/eurheartj/ehm076

Camelliti, P., Borg, T. K., and Kohl, P. (2005). Structural and functional characterisation of cardiac fibroblasts. Cardiovasc. Res. 65, 40-51. doi: 10.1016/ j.cardiores.2004.08.020

Chan, C. T., Sobey, C. G., Lieu, M., Ferens, D., Kett, M. M., Diep, H., et al. (2015). Obligatory role for B cells in the development of angiotensin II-dependent hypertension. Hypertension 66, 1023-1033. doi: 10.1161/hypertensionaha.115. 05779

Chen, W., Saxena, A., Li, N., Sun, J., Gupta, A., Lee, D. W., et al. (2012). Endogenous IRAK-M attenuates postinfarction remodeling through effects on macrophages and fibroblasts. Arterioscler. Thromb. Vasc. Biol. 32, 2598-2608. doi: 10.1161/atvbaha.112.300310

Choy, D. F., Hart, K. M., Borthwick, L. A., Shikotra, A., Nagarkar, D. R., Siddiqui, S., et al. (2015). TH2 and TH17 inflammatory pathways are reciprocally regulated in asthma. Sci. Transl. Med. 7:301ra129.

Christia, P., Bujak, M., Gonzalez-Quesada, C., Chen, W., Dobaczewski, M., Reddy, A., et al. (2013). Systematic characterization of myocardial inflammation, repair, and remodeling in a mouse model of reperfused myocardial infarction. J. Histochem. Cytochem. 61, 555-570. doi: 10.1369/0022155413493912

Chung, E. S., Packer, M., Lo, K. H., Fasanmade, A. A., Willerson, J. T., and Anti, T. N. F. T. A. C. H. F. I. (2003). Randomized, double-blind, placebo-controlled, pilot trial of infliximab, a chimeric monoclonal antibody to tumor necrosis factor-alpha, in patients with moderate-to-severe heart failure: results of the anti-TNF therapy against congestive heart failure (ATTACH) trial. Circulation 107, 3133-3140. doi: 10.1161/01.cir.0000077913.60364.d2

Ciz, M., Denev, P., Kratchanova, M., Vasicek, O., Ambrozova, G., and Lojek, A. (2012). Flavonoids inhibit the respiratory burst of neutrophils in mammals. Oxid. Med. Cell Longev. 2012:181295.

Clark, R. A., McCoy, G. A., Folkvord, J. M., and McPherson, J. M. (1997). TGF-beta 1 stimulates cultured human fibroblasts to proliferate and produce tissue-like fibroplasia: a fibronectin matrix-dependent event. J. Cell Physiol. 170, 69-80. doi: 10.1002/(sici)1097-4652(199701)170:1<69::aid-jcp8>3.0.co;2-j

Cleutjens, J. P., Kandala, J. C., Guarda, E., Guntaka, R. V., and Weber, K. T. (1995a). Regulation of collagen degradation in the rat myocardium after infarction. J. Mol. Cell. Cardiol. 27, 1281-1292. doi: 10.1016/s0022-2828(05)82390-9

Cleutjens, J. P., Verluyten, M. J., Smiths, J. F., and Daemen, M. J. (1995b). Collagen remodeling after myocardial infarction in the rat heart. Am. J. Pathol. 147, 325-338.

Cooper, L. T. Jr. (2009). Myocarditis. N. Engl. J. Med. 360, 1526-1538.

Cordero-Reyes, A. M., Youker, K. A., Trevino, A. R., Celis, R., Hamilton, D. J., Flores-Arredondo, J. H., et al. (2016). Full expression of cardiomyopathy is partly dependent on B-cells: a pathway that involves cytokine activation, immunoglobulin deposition, and activation of apoptosis. J. Am. Heart Assoc. 5, e002484.

Dean, R. A., Cox, J. H., Bellac, C. L., Doucet, A., Starr, A. E., and Overall, C. M. (2008). Macrophage-specific metalloelastase (MMP-12) truncates and inactivates ELR+ CXC chemokines and generates CCL2, $-7,-8$, and -13 antagonists: potential role of the macrophage in terminating polymorphonuclear leukocyte influx. Blood 112, 3455-3464. doi: 10.1182/ blood-2007-12-129080

Detillieux, K. A., Sheikh, F., Kardami, E., and Cattini, P. A. (2003). Biological activities of fibroblast growth factor-2 in the adult myocardium. Cardiovasc. Res. 57, 8-19. doi: 10.1016/s0008-6363(02)00708-3

Detmers, P. A., Lo, S. K., Olsen-Egbert, E., Walz, A., Baggiolini, M., and Cohn, Z. A. (1990). Neutrophil-activating protein $1 /$ interleukin 8 stimulates the binding activity of the leukocyte adhesion receptor CD11b/CD18 on human neutrophils. J. Exp. Med. 171, 1155-1162. doi: 10.1084/jem.171.4.1155 
Devi, S., Wang, Y., Chew, W. K., Lima, R., Gonzalez, N. A., Mattar, C. N., et al. (2013). Neutrophil mobilization via plerixafor-mediated CXCR4 inhibition arises from lung demargination and blockade of neutrophil homing to the bone marrow. J. Exp. Med. 210, 2321-2336. doi: 10.1084/jem.20130056

Dewald, O., Zymek, P., Winkelmann, K., Koerting, A., Ren, G., AbouKhamis, T., et al. (2005). CCL2/monocyte chemoattractant Protein-1 regulates inflammatory responses critical to healing myocardial infarcts. Circ. Res. 96, 881-889. doi: 10.1161/01.res.0000163017.13772.3a

Diaz-Araya, G., Vivar, R., Humeres, C., Boza, P., Bolivar, S., and Munoz, C. (2015). Cardiac fibroblasts as sentinel cells in cardiac tissue: receptors, signaling pathways and cellular functions. Pharmacol. Res. 101, 30-40. doi: 10.1016/j. phrs.2015.07.001

Dieterlen, M. T., John, K., Reichenspurner, H., Mohr, F. W., and Barten, M. J. (2016). Dendritic cells and their role in cardiovascular diseases: a view on human studies. J. Immunol. Res. 2016:5946807.

Dobaczewski, M., Bujak, M., Li, N., Gonzalez-Quesada, C., Mendoza, L. H., Wang, X. F., et al. (2010a). Smad3 signaling critically regulates fibroblast phenotype and function in healing myocardial infarction. Circ. Res. 107, 418-428. doi: 10.1161/circresaha.109.216101

Dobaczewski, M., Xia, Y., Bujak, M., Gonzalez-Quesada, C., and Frangogiannis, N. G. (2010b). CCR5 signaling suppresses inflammation and reduces adverse remodeling of the infarcted heart, mediating recruitment of regulatory $\mathrm{T}$ cells. Am. J. Pathol. 176, 2177-2187. doi: 10.2353/ajpath.2010.090759

Dobaczewski, M., Chen, W., and Frangogiannis, N. G. (2011). Transforming growth factor (TGF)-beta signaling in cardiac remodeling. J. Mol. Cell Cardiol. 51, 600-606. doi: 10.1016/j.yjmcc.2010.10.033

Drummond, G. R., Vinh, A., Guzik, T. J., and Sobey, C. G. (2019). Immune mechanisms of hypertension. Nat. Rev. Immunol. 19, 517-532.

Entman, M. L., Youker, K., Shoji, T., Kukielka, G., Shappell, S. B., Taylor, A. A., et al. (1992). Neutrophil induced oxidative injury of cardiac myocytes. A compartmented system requiring CD11b/CD18-ICAM-1 adherence. J. Clin. Invest. 90, 1335-1345. doi: 10.1172/jci115999

Epelman, S., Lavine, K. J., Beaudin, A. E., Sojka, D. K., Carrero, J. A., Calderon, B., et al. (2014). Embryonic and adult-derived resident cardiac macrophages are maintained through distinct mechanisms at steady state and during inflammation. Immunity 40, 91-104. doi: 10.1016/j.immuni.2013.11.019

Evans, S., Tzeng, H. P., Veis, D. J., Matkovich, S., Weinheimer, C., Kovacs, A., et al. (2018). TNF receptor-activated factor 2 mediates cardiac protection through noncanonical NF-kappaB signaling. JCI Insight. 3:e98278.

Fertin, C., Nicolas, J. F., Gillery, P., Kalis, B., Banchereau, J., and Maquart, F. X. (1991). Interleukin-4 stimulates collagen synthesis by normal and scleroderma fibroblasts in dermal equivalents. Cell Mol. Biol. 37, 823-829.

Fildes, J. E., Shaw, S. M., Yonan, N., and Williams, S. G. (2009). The immune system and chronic heart failure: is the heart in control? J. Am. Coll. Cardiol. 53, 1013-1020.

Fine, A., and Goldstein, R. H. (1987). The effect of transforming growth factor-beta on cell proliferation and collagen formation by lung fibroblasts. J. Biol. Chem. 262, 3897-3902.

Finkel, M. S., Oddis, C. V., Jacob, T. D., Watkins, S. C., Hattler, B. G., and Simmons, R. L. (1992). Negative inotropic effects of cytokines on the heart mediated by nitric oxide. Science 257, 387-389. doi: 10.1126/science. 1631560

Fiorentino, D. F., Zlotnik, A., Mosmann, T. R., Howard, M., and O'Garra, A. (1991). IL-10 inhibits cytokine production by activated macrophages. J. Immunol. 147, 3815-3822.

Frangogiannis, N. G., Burns, A. R., Michael, L. H., and Entman, M. L. (1999). Histochemical and morphological characteristics of canine cardiac mast cells. Histochem. J. 31, 221-229.

Frangogiannis, N. G., Lindsey, M. L., Michael, L. H., Youker, K. A., Bressler, R. B., Mendoza, L. H., et al. (1998a). Resident cardiac mast cells degranulate and release preformed TNF-alpha, initiating the cytokine cascade in experimental canine myocardial ischemia/reperfusion. Circulation 98, 699-710. doi: 10.1161/ 01.cir.98.7.699

Frangogiannis, N. G., Perrard, J. L., Mendoza, L. H., Burns, A. R., Lindsey, M. L., Ballantyne, C. M., et al. (1998b). Stem cell factor induction is associated with mast cell accumulation after canine myocardial ischemia and reperfusion. Circulation 98, 687-698. doi: 10.1161/01.cir.98.7.687

Frangogiannis, N. G., Mendoza, L. H., Lindsey, M. L., Ballantyne, C. M., Michael, L. H., Smith, C. W., et al. (2000a). IL-10 is induced in the reperfused myocardium and may modulate the reaction to injury. J. Immunol. 165, 27982808. doi: 10.4049/jimmunol.165.5.2798

Frangogiannis, N. G., Michael, L. H., and Entman, M. L. (2000b). Myofibroblasts in reperfused myocardial infarcts express the embryonic form of smooth muscle myosin heavy chain (SMemb). Cardiovasc. Res. 48, 89-100. doi: 10.1016/s00086363(00)00158-9

Franken, L., Schiwon, M., and Kurts, C. (2016). Macrophages: sentinels and regulators of the immune system. Cell Microbiol. 18, 475-487. doi: 10.1111/ cmi. 12580

Frantz, S., Kobzik, L., Kim, Y. D., Fukazawa, R., Medzhitov, R., Lee, R. T., et al. (1999). Toll4 (TLR4) expression in cardiac myocytes in normal and failing myocardium. J. Clin. Invest. 104, 271-280. doi: 10.1172/jci6709

Fredj, S., Bescond, J., Louault, C., and Potreau, D. (2005). Interactions between cardiac cells enhance cardiomyocyte hypertrophy and increase fibroblast proliferation. J. Cell Physiol. 202, 891-899. doi: 10.1002/jcp.20197

Freed, D. H., Chilton, L., Li, Y., Dangerfield, A. L., Raizman, J. E., Rattan, S. G., et al. (2011). Role of myosin light chain kinase in cardiotrophin-1-induced cardiac myofibroblast cell migration. Am. J. Physiol. Heart Circ. Physiol. 301, H514-H522.

Fung, G., Luo, H., Qiu, Y., Yang, D., and McManus, B. (2016). Myocarditis. Circ. Res. 118, 496-514.

Geering, B., Stoeckle, C., Conus, S., and Simon, H. U. (2013). Living and dying for inflammation: neutrophils, eosinophils, basophils. Trends Immunol. 34, 398-409. doi: 10.1016/j.it.2013.04.002

Getts, D. R., Terry, R. L., Getts, M. T., Deffrasnes, C., Muller, M., van Vreden, C., et al. (2014). Therapeutic inflammatory monocyte modulation using immune-modifying microparticles. Sci. Transl. Med. 6:219ra7. doi: 10.1126/ scitranslmed.3007563

Gittenberger-de Groot, A. C., Vrancken Peeters, M. P., Mentink, M. M., Gourdie, R. G., and Poelmann, R. E. (1998). Epicardium-derived cells contribute a novel population to the myocardial wall and the atrioventricular cushions. Circ. Res. 82, 1043-1052. doi: 10.1161/01.res.82.10.1043

Gondokaryono, S. P., Ushio, H., Niyonsaba, F., Hara, M., Takenaka, H., Jayawardana, S. T., et al. (2007). The extra domain A of fibronectin stimulates murine mast cells via toll-like receptor 4. J. Leukoc. Biol. 82, 657-665. doi: 10.1189/jlb.1206730

Gonzalez, G. E., Rhaleb, N. E., D’Ambrosio, M. A., Nakagawa, P., Liu, Y., Leung, P., et al. (2015). Deletion of interleukin-6 prevents cardiac inflammation, fibrosis and dysfunction without affecting blood pressure in angiotensin IIhigh salt-induced hypertension. J. Hypertens. 33, 144-152. doi: 10.1097/hjh. 0000000000000358

Grisanti, L. A., Traynham, C. J., Repas, A. A., Gao, E., Koch, W. J., and Tilley, D. G. (2016). beta2-Adrenergic receptor-dependent chemokine receptor 2 expression regulates leukocyte recruitment to the heart following acute injury. Proc. Natl. Acad. Sci. U.S.A. 113, 15126-15131. doi: 10.1073/pnas.1611023114

Guillen, I., Blanes, M., Gomez-Lechon, M. J., and Castell, J. V. (1995). Cytokine signaling during myocardial infarction: sequential appearance of IL-1 beta and IL-6. Am. J. Physiol. 269(2 Pt 2), R229-R235.

Guthrie, L. A., McPhail, L. C., Henson, P. M., and Johnston, R. B. Jr. (1984). Priming of neutrophils for enhanced release of oxygen metabolites by bacterial lipopolysaccharide. Evidence for increased activity of the superoxide-producing enzyme. J. Exp. Med. 160, 1656-1671. doi: 10.1084/jem.160.6.1656

Guzik, T. J., Hoch, N. E., Brown, K. A., McCann, L. A., Rahman, A., Dikalov, S., et al. (2007). Role of the $\mathrm{T}$ cell in the genesis of angiotensin II induced hypertension and vascular dysfunction. J. Exp. Med. 204, 2449-2460. doi: 10.1084/jem.20070657

Han, Y. L., Li, Y. L., Jia, L. X., Cheng, J. Z., Qi, Y. F., Zhang, H. J., et al. (2012). Reciprocal interaction between macrophages and $T$ cells stimulates IFN-gamma and MCP-1 production in Ang II-induced cardiac inflammation and fibrosis. PLoS One 7:e35506. doi: 10.1371/journal.pone.035506

Hara, M., Ono, K., Hwang, M. W., Iwasaki, A., Okada, M., Nakatani, K., et al. (2002). Evidence for a role of mast cells in the evolution to congestive heart failure. J. Exp. Med. 195, 375-381. doi: 10.1084/jem.2000 2036

Harrison, D. G. (2014). The immune system in hypertension. Trans. Am. Clin. Climatol. Assoc. 125, 130-138.

Hart, P. H., Vitti, G. F., Burgess, D. R., Whitty, G. A., Piccoli, D. S., and Hamilton, J. A. (1989). Potential antiinflammatory effects of interleukin 4: suppression of 
human monocyte tumor necrosis factor alpha, interleukin 1, and prostaglandin E2. Proc. Natl. Acad. Sci. U.S.A. 86, 3803-3807. doi: 10.1073/pnas.86.10.3803

Hashimoto, S., Gon, Y., Takeshita, I., Matsumoto, K., Maruoka, S., and Horie, T. (2001). Transforming growth Factor-betal induces phenotypic modulation of human lung fibroblasts to myofibroblast through a c-Jun-NH2-terminal kinasedependent pathway. Am. J. Respir. Crit. Care Med. 163, 152-157. doi: 10.1164/ ajrccm.163.1.2005069

Haudek, S. B., Xia, Y., Huebener, P., Lee, J. M., Carlson, S., Crawford, J. R., et al. (2006). Bone marrow-derived fibroblast precursors mediate ischemic cardiomyopathy in mice. Proc. Natl. Acad. Sci. U.S.A. 103, 18284-18289. doi: $10.1073 /$ pnas.0608799103

Heidt, T., Courties, G., Dutta, P., Sager, H. B., Sebas, M., Iwamoto, Y., et al. (2014). Differential contribution of monocytes to heart macrophages in steadystate and after myocardial infarction. Circ. Res. 115, 284-295. doi: 10.1161/ circresaha.115.303567

Heim, A., Zeuke, S., Weiss, S., Ruschewski, W., and Grumbach, I. M. (2000). Transient induction of cytokine production in human myocardial fibroblasts by coxsackievirus B3. Circ. Res. 86, 753-759. doi: 10.1161/01.res.86.7.753

Herskowitz, A., Choi, S., Ansari, A. A., and Wesselingh, S. (1995). Cytokine mRNA expression in postischemic/reperfused myocardium. Am. J. Pathol. 146, 419-428.

Herter, J., and Zarbock, A. (2013). Integrin regulation during leukocyte recruitment. J. Immunol. 190, 4451-4457. doi: 10.4049/jimmunol.1203179

Hilgendorf, I., Gerhardt, L. M., Tan, T. C., Winter, C., Holderried, T. A., Chousterman, B. G., et al. (2014). Ly-6Chigh monocytes depend on Nr4al to balance both inflammatory and reparative phases in the infarcted myocardium. Circ. Res. 114, 1611-1622. doi: 10.1161/circresaha.114.303204

Hofmann, U., Beyersdorf, N., Weirather, J., Podolskaya, A., Bauersachs, J., Ertl, G., et al. (2012). Activation of CD4+ T lymphocytes improves wound healing and survival after experimental myocardial infarction in mice. Circulation 125, 1652-1663. doi: 10.1161/circulationaha.111.044164

Hofmann, U., Knorr, S., Vogel, B., Weirather, J., Frey, A., Ertl, G., et al. (2014). Interleukin-13 deficiency aggravates healing and remodeling in male mice after experimental myocardial infarction. Circ. Heart Fail. 7, 822-830. doi: 10.1161/ circheartfailure.113.001020

Homma, T., Kinugawa, S., Takahashi, M., Sobirin, M. A., Saito, A., Fukushima, A., et al. (2013). Activation of invariant natural killer $\mathrm{T}$ cells by alphagalactosylceramide ameliorates myocardial ischemia/reperfusion injury in mice. J. Mol. Cell Cardiol. 62, 179-188. doi: 10.1016/j.yjmcc.2013.06.004

Horckmans, M., Ring, L., Duchene, J., Santovito, D., Schloss, M. J., Drechsler, M., et al. (2017). Neutrophils orchestrate post-myocardial infarction healing by polarizing macrophages towards a reparative phenotype. Eur. Heart J. 38, 187-197.

Huang, W. C., Sala-Newby, G. B., Susana, A., Johnson, J. L., and Newby, A. C. (2012). Classical macrophage activation up-regulates several matrix metalloproteinases through mitogen activated protein kinases and nuclear factor-kappaB. PLoS One 7:e42507. doi: 10.1371/journal.pone.0042507

Hulsmans, M., Clauss, S., Xiao, L., Aguirre, A. D., King, K. R., Hanley, A., et al. (2017). Macrophages facilitate electrical conduction in the heart. Cell 169, 510-522.e10.

Hwang, M. W., Matsumori, A., Furukawa, Y., Ono, K., Okada, M., Iwasaki, A., et al. (2001). Neutralization of interleukin-1beta in the acute phase of myocardial infarction promotes the progression of left ventricular remodeling. J. Am. Coll. Cardiol. 38, 1546-1553. doi: 10.1016/s0735-1097(01)01591-1

Ikeuchi, M., Tsutsui, H., Shiomi, T., Matsusaka, H., Matsushima, S., Wen, J., et al. (2004). Inhibition of TGF-beta signaling exacerbates early cardiac dysfunction but prevents late remodeling after infarction. Cardiovasc. Res. 64, 526-535. doi: 10.1016/j.cardiores.2004.07.017

Ilatovskaya, D. V., Pitts, C., Clayton, J., Domondon, M., Troncoso, M., Pippin, S., et al. (2019). CD8(+) T-cells negatively regulate inflammation post-myocardial infarction. Am. J. Physiol. Heart Circ. Physiol. 317, H581-H596.

Ivashkiv, L. B., and Donlin, L. T. (2014). Regulation of type I interferon responses. Nat. Rev. Immunol. 14, 36-49. doi: 10.1038/nri3581

Kai, H., Mori, T., Tokuda, K., Takayama, N., Tahara, N., Takemiya, K., et al. (2006). Pressure overload-induced transient oxidative stress mediates perivascular inflammation and cardiac fibrosis through angiotensin II. Hypertens. Res. 29, 711-718. doi: 10.1291/hypres.29.711
Kanellakis, P., Ditiatkovski, M., Kostolias, G., and Bobik, A. (2012). A pro-fibrotic role for interleukin-4 in cardiac pressure overload. Cardiovasc. Res. 95, 77-85. doi: $10.1093 / \mathrm{cvr} / \mathrm{cvs} 142$

Katayama, Y., Battista, M., Kao, W. M., Hidalgo, A., Peired, A. J., Thomas, S. A., et al. (2006). Signals from the sympathetic nervous system regulate hematopoietic stem cell egress from bone marrow. Cell 124, 407-421. doi: 10.1016/j.cell.2005.10.041

Kawaguchi, M., Takahashi, M., Hata, T., Kashima, Y., Usui, F., Morimoto, H., et al. (2011). Inflammasome activation of cardiac fibroblasts is essential for myocardial ischemia/reperfusion injury. Circulation 123, 594-604. doi: 10. 1161/circulationaha.110.982777

Kempf, T., Bjorklund, E., Olofsson, S., Lindahl, B., Allhoff, T., Peter, T., et al. (2007). Growth-differentiation factor-15 improves risk stratification in STsegment elevation myocardial infarction. Eur. Heart J. 28, 2858-2865. doi: 10.1093/eurheartj/ehm465

Kempf, T., Zarbock, A., Widera, C., Butz, S., Stadtmann, A., Rossaint, J., et al. (2011). GDF-15 is an inhibitor of leukocyte integrin activation required for survival after myocardial infarction in mice. Nat. Med. 17, 581-588. doi: 10. 1038/nm.2354

Khokha, R., Murthy, A., and Weiss, A. (2013). Metalloproteinases and their natural inhibitors in inflammation and immunity. Nat. Rev. Immunol. 13, 649-665. doi: 10.1038/nri3499

Kimura, A., Ishida, Y., Furuta, M., Nosaka, M., Kuninaka, Y., Taruya, A., et al. (2018). Protective roles of interferon-gamma in cardiac hypertrophy induced by sustained pressure overload. J. Am. Heart Assoc. 7:e008145.

Kindermann, I., Kindermann, M., Kandolf, R., Klingel, K., Bultmann, B., Muller, T., et al. (2008). Predictors of outcome in patients with suspected myocarditis. Circulation 118, 639-648. doi: 10.1161/circulationaha.108.769489

Kisanuki, Y. Y., Hammer, R. E., Miyazaki, J., Williams, S. C., Richardson, J. A., and Yanagisawa, M. (2001). Tie2-Cre transgenic mice: a new model for endothelial cell-lineage analysis in vivo. Dev. Biol. 230, 230-242. doi: 10.1006/dbio.2000. 0106

Kong, P., Christia, P., Saxena, A., Su, Y., and Frangogiannis, N. G. (2013). Lack of specificity of fibroblast-specific protein 1 in cardiac remodeling and fibrosis. Am. J. Physiol. Heart Circ. Physiol. 305, H1363-H1372.

Kono, H., Chen, C. J., Ontiveros, F., and Rock, K. L. (2010). Uric acid promotes an acute inflammatory response to sterile cell death in mice. J. Clin. Invest. 120, 1939-1949. doi: 10.1172/jci40124

Koudssi, F., Lopez, J. E., Villegas, S., and Long, C. S. (1998). Cardiac fibroblasts arrest at the G1/S restriction point in response to interleukin (IL)-1beta. Evidence for IL-1beta-induced hypophosphorylation of the retinoblastoma protein. J. Biol. Chem. 273, 25796-25803. doi: 10.1074/jbc.273.40.25796

Kramann, R., Schneider, R. K., DiRocco, D. P., Machado, F., Fleig, S., Bondzie, P. A., et al. (2015). Perivascular Gli1+ progenitors are key contributors to injuryinduced organ fibrosis. Cell Stem Cell 16, 51-66. doi: 10.1016/j.stem.2014.11. 004

Kukielka, G. L., Hawkins, H. K., Michael, L., Manning, A. M., Youker, K., Lane, C., et al. (1993). Regulation of intercellular adhesion molecule-1 (ICAM-1) in ischemic and reperfused canine myocardium. J. Clin. Invest. 92, 1504-1516. doi: $10.1172 /$ jci116729

Kumar, A. G., Ballantyne, C. M., Michael, L. H., Kukielka, G. L., Youker, K. A., Lindsey, M. L., et al. (1997). Induction of monocyte chemoattractant protein1 in the small veins of the ischemic and reperfused canine myocardium. Circulation 95, 693-700. doi: 10.1161/01.cir.95.3.693

Kurrelmeyer, K. M., Michael, L. H., Baumgarten, G., Taffet, G. E., Peschon, J. J., Sivasubramanian, N., et al. (2000). Endogenous tumor necrosis factor protects the adult cardiac myocyte against ischemic-induced apoptosis in a murine model of acute myocardial infarction. Proc. Natl. Acad. Sci. U.S.A. 97, 5456-5461. doi: 10.1073/pnas.070036297

Lacraz, S., Nicod, L. P., Chicheportiche, R., Welgus, H. G., and Dayer, J. M. (1995). IL-10 inhibits metalloproteinase and stimulates TIMP-1 production in human mononuclear phagocytes. J. Clin. Invest. 96, 2304-2310. doi: 10.1172/jci118286

Lafontant, P. J., Burns, A. R., Donnachie, E., Haudek, S. B., Smith, C. W., and Entman, M. L. (2006). Oncostatin M differentially regulates CXC chemokines in mouse cardiac fibroblasts. Am. J. Physiol. Cell Physiol. 291, C18-C26.

Lakshminarayanan, V., Beno, D. W., Costa, R. H., and Roebuck, K. A. (1997). Differential regulation of interleukin-8 and intercellular adhesion molecule-1 
by $\mathrm{H} 2 \mathrm{O} 2$ and tumor necrosis factor-alpha in endothelial and epithelial cells. J. Biol. Chem. 272, 32910-32918. doi: 10.1074/jbc.272.52.32910

Lakshminarayanan, V., Lewallen, M., Frangogiannis, N. G., Evans, A. J., Wedin, K. E., Michael, L. H., et al. (2001). Reactive oxygen intermediates induce monocyte chemotactic protein-1 in vascular endothelium after brief ischemia. Am. J. Pathol. 159, 1301-1311. doi: 10.1016/s0002-9440(10)62517-5

Laroumanie, F., Douin-Echinard, V., Pozzo, J., Lairez, O., Tortosa, F., Vinel, C., et al. (2014). CD4+ T cells promote the transition from hypertrophy to heart failure during chronic pressure overload. Circulation 129, 2111-2124. doi: 10.1161/circulationaha.113.007101

Lee, J. W., Oh, J. E., Rhee, K. J., Yoo, B. S., Eom, Y. W., Park, S. W., et al. (2019). Co-treatment with interferon-gamma and 1-methyl tryptophan ameliorates cardiac fibrosis through cardiac myofibroblasts apoptosis. Mol. Cell Biochem. 458, 197-205. doi: 10.1007/s11010-019-03542-7

Lefebvre, J. S., Levesque, T., Picard, S., Pare, G., Gravel, A., Flamand, L., et al. (2011). Extra domain A of fibronectin primes leukotriene biosynthesis and stimulates neutrophil migration through activation of Toll-like receptor 4. Arthrit. Rheum. 63, 1527-1533. doi: 10.1002/art.30308

Leuschner, F., Dutta, P., Gorbatov, R., Novobrantseva, T. I., Donahoe, J. S., Courties, G., et al. (2011). Therapeutic siRNA silencing in inflammatory monocytes in mice. Nat. Biotechnol. 29, 1005-1010.

Levick, S. P., McLarty, J. L., Murray, D. B., Freeman, R. M., Carver, W. E., and Brower, G. L. (2009). Cardiac mast cells mediate left ventricular fibrosis in the hypertensive rat heart. Hypertension 53, 1041-1047. doi: 10.1161/ hypertensionaha.108.123158

Levings, M. K., and Schrader, J. W. (1999). IL-4 inhibits the production of TNF-alpha and IL-12 by STAT6-dependent and -independent mechanisms. J. Immunol. 162, 5224-5229.

Ley, K., Laudanna, C., Cybulsky, M. I., and Nourshargh, S. (2007). Getting to the site of inflammation: the leukocyte adhesion cascade updated. Nat. Rev. Immunol. 7, 678-689. doi: 10.1038/nri2156

Li, C., Sun, X. N., Zeng, M. R., Zheng, X. J., Zhang, Y. Y., Wan, Q., et al. (2017). Mineralocorticoid receptor deficiency in $\mathrm{T}$ cells attenuates pressure overload-induced cardiac hypertrophy and dysfunction through modulating T-cell activation. Hypertension 70, 137-147. doi: 10.1161/hypertensionaha.117. 09070

Li, J., Schwimmbeck, P. L., Tschope, C., Leschka, S., Husmann, L., Rutschow, S., et al. (2002). Collagen degradation in a murine myocarditis model: relevance of matrix metalloproteinase in association with inflammatory induction. Cardiovasc. Res. 56, 235-247. doi: 10.1016/s0008-6363(02)00546-1

Li, Y., Wu, Y., Zhang, C., Li, P., Cui, W., Hao, J., et al. (2014). gammadeltaT Cell-derived interleukin-17A via an interleukin-1beta-dependent mechanism mediates cardiac injury and fibrosis in hypertension. Hypertension 64, 305-314. doi: 10.1161/hypertensionaha.113.02604

Li, Y., Zhang, C., Wu, Y., Han, Y., Cui, W., Jia, L., et al. (2012). Interleukin12 p35 deletion promotes CD4 T-cell-dependent macrophage differentiation and enhances angiotensin II-Induced cardiac fibrosis. Arterioscler. Thromb. Vasc. Biol. 32, 1662-1674. doi: 10.1161/atvbaha.112.249706

Liao, X., Shen, Y., Zhang, R., Sugi, K., Vasudevan, N. T., Alaiti, M. A., et al. (2018). Distinct roles of resident and nonresident macrophages in nonischemic cardiomyopathy. Proc. Natl. Acad. Sci. U.S.A. 115, E4661-E4669.

Liao, Y. H., Xia, N., Zhou, S. F., Tang, T. T., Yan, X. X., Lv, B. J., et al. (2012). Interleukin-17A contributes to myocardial ischemia/reperfusion injury by regulating cardiomyocyte apoptosis and neutrophil infiltration. J. Am. Coll. Cardiol. 59, 420-429. doi: 10.1016/j.jacc.2011.10.863

Lijnen, P., Papparella, I., Petrov, V., Semplicini, A., and Fagard, R. (2006). Angiotensin II-stimulated collagen production in cardiac fibroblasts is mediated by reactive oxygen species. J. Hypertens. 24, 757-766. doi: 10.1097/ 01.hjh.0000217860.04994.54

Lipps, C., Nguyen, J. H., Pyttel, L., Lynch, T. L. T., Liebetrau, C., Aleshcheva, G., et al. (2016). N-terminal fragment of cardiac myosin binding protein-C triggers pro-inflammatory responses in vitro. J. Mol. Cell Cardiol. 99, 47-56. doi: 10.1016/j.yjmcc.2016.09.003

Liu, T., Song, D., Dong, J., Zhu, P., Liu, J., Liu, W., et al. (2017). Current understanding of the pathophysiology of myocardial fibrosis and its quantitative assessment in heart failure. Front. Physiol. 8:238. doi: 10.3389/ fphys.2017.00238
Liu, Y. R., Ye, W. L., Zeng, X. M., Ren, W. H., Zhang, Y. Q., and Mei, Y. A. K. (2008). + channels and the cAMP-PKA pathway modulate TGF-beta1-induced migration of rat vascular myofibroblasts. J. Cell Physiol. 216, 835-843. doi: $10.1002 /$ jcp. 21464

Lotze, M. T., and Tracey, K. J. (2005). High-mobility group box 1 protein (HMGB1): nuclear weapon in the immune arsenal. Nat. Rev. Immunol. 5, 331-342. doi: 10.1038/nri1594

Lu, D., Soleymani, S., Madakshire, R., and Insel, P. A. (2012). ATP released from cardiac fibroblasts via connexin hemichannels activates profibrotic P2Y2 receptors. FASEB J. 26, 2580-2591. doi: 10.1096/fj.12-204677

Machaj, F., Dembowska, E., Rosik, J., Szostak, B., Mazurek-Mochol, M., and Pawlik, A. (2019). New therapies for the treatment of heart failure: a summary of recent accomplishments. Ther. Clin. Risk Manag. 15, 147-155. doi: 10.2147/tcrm. s179302

Maekawa, N., Wada, H., Kanda, T., Niwa, T., Yamada, Y., Saito, K., et al. (2002). Improved myocardial ischemia/reperfusion injury in mice lacking tumor necrosis factor-alpha. J. Am. Coll. Cardiol. 39, 1229-1235. doi: 10.1016/s07351097(02)01738-2

Mann, D. L. (2011). The emerging role of innate immunity in the heart and vascular system: for whom the cell tolls. Circ. Res. 108, 1133-1145. doi: 10. 1161/circresaha.110.226936

Mann, D. L., McMurray, J. J., Packer, M., Swedberg, K., Borer, J. S., Colucci, W. S., et al. (2004). Targeted anticytokine therapy in patients with chronic heart failure: results of the randomized etanercept worldwide evaluation (RENEWAL). Circulation 109, 1594-1602. doi: 10.1161/01.cir.0000124490. 27666.b2

Mantovani, A., Cassatella, M. A., Costantini, C., and Jaillon, S. (2011). Neutrophils in the activation and regulation of innate and adaptive immunity. Nat. Rev. Immunol. 11, 519-531. doi: 10.1038/nri3024

Marko, L., Kvakan, H., Park, J. K., Qadri, F., Spallek, B., Binger, K. J., et al. (2012). Interferon-gamma signaling inhibition ameliorates angiotensin II-induced cardiac damage. Hypertension 60, 1430-1436. doi: 10.1161/hypertensionaha. 112.199265

McDonald, B., Pittman, K., Menezes, G. B., Hirota, S. A., Slaba, I., Waterhouse, C. C., et al. (2010). Intravascular danger signals guide neutrophils to sites of sterile inflammation. Science 330, 362-366. doi: 10.1126/science.1195491

Merline, R., Moreth, K., Beckmann, J., Nastase, M. V., Zeng-Brouwers, J., Tralhao, J. G., et al. (2011). Signaling by the matrix proteoglycan decorin controls inflammation and cancer through PDCD4 and MicroRNA-21. Sci. Signal. 4:ra75. doi: 10.1126/scisignal.2001868

Mitchell, M. D., Laird, R. E., Brown, R. D., and Long, C. S. (2007). IL-1beta stimulates rat cardiac fibroblast migration via MAP kinase pathways. Am. J. Physiol. Heart Circ. Physiol. 292, H1139-H1147.

Mollmann, H., Nef, H. M., Kostin, S., von Kalle, C., Pilz, I., Weber, M., et al. (2006). Bone marrow-derived cells contribute to infarct remodelling. Cardiovasc. Res. 71, 661-671. doi: 10.1016/j.cardiores.2006.06.013

Monden, Y., Kubota, T., Inoue, T., Tsutsumi, T., Kawano, S., Ide, T., et al. (2007a). Tumor necrosis factor-alpha is toxic via receptor 1 and protective via receptor 2 in a murine model of myocardial infarction. Am. J. Physiol. Heart Circ. Physiol. 293, H743-H753.

Monden, Y., Kubota, T., Tsutsumi, T., Inoue, T., Kawano, S., Kawamura, N., et al. (2007b). Soluble TNF receptors prevent apoptosis in infiltrating cells and promote ventricular rupture and remodeling after myocardial infarction. Cardiovasc. Res. 73, 794-805. doi: 10.1016/j.cardiores.2006. 12.016

Monvoisin, A., Alva, J. A., Hofmann, J. J., Zovein, A. C., Lane, T. F., and IruelaArispe, M. L. (2006). VE-cadherin-CreERT2 transgenic mouse: a model for inducible recombination in the endothelium. Dev. Dyn. 235, 3413-3422. doi: 10.1002/dvdy.20982

Moore-Morris, T., Cattaneo, P., Guimaraes-Camboa, N., Bogomolovas, J., Cedenilla, M., Banerjee, I., et al. (2018). Infarct fibroblasts do not derive from bone marrow lineages. Circ. Res. 122, 583-590. doi: 10.1161/circresaha.117. 311490

Moore-Morris, T., Guimaraes-Camboa, N., Banerjee, I., Zambon, A. C., Kisseleva, T., Velayoudon, A., et al. (2014). Resident fibroblast lineages mediate pressure overload-induced cardiac fibrosis. J. Clin. Invest. 124, 2921-2934. doi: 10.1172/ jci74783 
Mosmann, T. R., and Coffman, R. L. (1989). TH1 and TH2 cells: different patterns of lymphokine secretion lead to different functional properties. Annu. Rev. Immunol. 7, 145-173. doi: 10.1146/annurev.iy.07.040189.001045

Muller, J., Gorressen, S., Grandoch, M., Feldmann, K., Kretschmer, I., Lehr, S., et al. (2014). Interleukin-6-dependent phenotypic modulation of cardiac fibroblasts after acute myocardial infarction. Basic Res. Cardiol. 109:440.

Murphy, S. P., Kakkar, R., McCarthy, C. P., and Januzzi, J. L. Jr. (2020). Inflammation in heart failure: JACC State-of-the-art review. J. Am. Coll. Cardiol. 75, 1324-1340.

Mylonas, K. J., Jenkins, S. J., Castellan, R. F., Ruckerl, D., McGregor, K., PhythianAdams, A. T., et al. (2015). The adult murine heart has a sparse, phagocytically active macrophage population that expands through monocyte recruitment and adopts an 'M2' phenotype in response to Th2 immunologic challenge. Immunobiology 220, 924-933. doi: 10.1016/j.imbio.2015.01.013

Nag, A. C. (1980). Study of non-muscle cells of the adult mammalian heart: a fine structural analysis and distribution. Cytobios 28, 41-61.

Nahrendorf, M., Swirski, F. K., Aikawa, E., Stangenberg, L., Wurdinger, T., Figueiredo, J. L., et al. (2007). The healing myocardium sequentially mobilizes two monocyte subsets with divergent and complementary functions. J. Exp. Med. 204, 3037-3047. doi: 10.1084/jem.20070885

Nazari, M., Ni, N. C., Ludke, A., Li, S. H., Guo, J., Weisel, R. D., et al. (2016). Mast cells promote proliferation and migration and inhibit differentiation of mesenchymal stem cells through PDGF. J. Mol. Cell Cardiol. 94, 32-42. doi: 10.1016/j.yjmcc.2016.03.007

Nevers, T., Salvador, A. M., Grodecki-Pena, A., Knapp, A., Velazquez, F., Aronovitz, M., et al. (2015). Left ventricular T-Cell recruitment contributes to the pathogenesis of heart failure. Circ. Heart Fail. 8, 776-787. doi: 10.1161/ circheartfailure.115.002225

Noppert, S. J., Fitzgerald, K. A., and Hertzog, P. J. (2007). The role of type I interferons in TLR responses. Immunol. Cell Biol. 85, 446-457. doi: 10.1038/ sj.icb.7100099

Oriente, A., Fedarko, N. S., Pacocha, S. E., Huang, S. K., Lichtenstein, L. M., and Essayan, D. M. (2000). Interleukin-13 modulates collagen homeostasis in human skin and keloid fibroblasts. J. Pharmacol. Exper. Therap. 292, 988-994.

Palmer, J. N., Hartogensis, W. E., Patten, M., Fortuin, F. D., and Long, C. S. (1995). Interleukin-1 beta induces cardiac myocyte growth but inhibits cardiac fibroblast proliferation in culture. J. Clin. Invest. 95, 2555-2564. doi: 10.1172/ jci117956

Patel, B., Bansal, S. S., Ismahil, M. A., Hamid, T., Rokosh, G., Mack, M., et al. (2018). CCR2(+) Monocyte-derived infiltrating macrophages are required for adverse cardiac remodeling during pressure overload. JACC Basic Transl. Sci. 3, 230-244. doi: 10.1016/j.jacbts.2017.12.006

Patella, V., Marino, I., Arbustini, E., Lamparter-Schummert, B., Verga, L., Adt, M., et al. (1998). Stem cell factor in mast cells and increased mast cell density in idiopathic and ischemic cardiomyopathy. Circulation 97, 971-978. doi: 10.1161/01.cir.97.10.971

Penberthy, K. K., and Ravichandran, K. S. (2016). Apoptotic cell recognition receptors and scavenger receptors. Immunol. Rev. 269, 44-59. doi: 10.1111/ imr.12376

Peng, H., Sarwar, Z., Yang, X. P., Peterson, E. L., Xu, J., Janic, B., et al. (2015). Profibrotic role for interleukin-4 in cardiac remodeling and dysfunction. Hypertension 66, 582-589. doi: 10.1161/hypertensionaha.115.05627

Petri, B., Phillipson, M., and Kubes, P. (2008). The physiology of leukocyte recruitment: an in vivo perspective. J. Immunol. 180, 6439-6446. doi: 10.4049/ jimmunol.180.10.6439

Pinto, A. R., Ilinykh, A., Ivey, M. J., Kuwabara, J. T., D’Antoni, M. L., Debuque, R., et al. (2016). Revisiting cardiac cellular composition. Circ. Res. 118, 400-409. doi: 10.1161/circresaha.115.307778

Pinto, A. R., Paolicelli, R., Salimova, E., Gospocic, J., Slonimsky, E., Bilbao-Cortes, D., et al. (2012). An abundant tissue macrophage population in the adult murine heart with a distinct alternatively-activated macrophage profile. PLoS One 7:e36814. doi: 10.1371/journal.pone.0036814

Postlethwaite, A. E., Holness, M. A., Katai, H., and Raghow, R. (1992). Human fibroblasts synthesize elevated levels of extracellular matrix proteins in response to interleukin 4. J. Clin. Invest. 90, 1479-1485. doi: 10.1172/jci116015

Prabhu, S. D., and Frangogiannis, N. G. (2016). The biological basis for cardiac repair after myocardial infarction: from inflammation to fibrosis. Circ. Res. 119, 91-112. doi: 10.1161/circresaha.116.303577
Pruenster, M., Mudde, L., Bombosi, P., Dimitrova, S., Zsak, M., Middleton, J., et al. (2009). The Duffy antigen receptor for chemokines transports chemokines and supports their promigratory activity. Nat. Immunol. 10, 101-108. doi: 10.1038/ni.1675

Puhl, S. L., and Steffens, S. (2019). Neutrophils in Post-myocardial Infarction inflammation: damage vs. resolution? Front. Cardiovasc. Med. 6:25. doi: 10. 3389/fphys.2017.00025

Rainer, P. P., Hao, S., Vanhoutte, D., Lee, D. I., Koitabashi, N., Molkentin, J. D., et al. (2014). Cardiomyocyte-specific transforming growth factor beta suppression blocks neutrophil infiltration, augments multiple cytoprotective cascades, and reduces early mortality after myocardial infarction. Circ. Res. 114, 1246-1257. doi: 10.1161/circresaha.114.302653

Ridker, P. M., Everett, B. M., Thuren, T., MacFadyen, J. G., Chang, W. H., Ballantyne, C., et al. (2017). Antiinflammatory therapy with canakinumab for atherosclerotic disease. N. Engl. J. Med. 377, 11191131.

Rienks, M., Papageorgiou, A. P., Frangogiannis, N. G., and Heymans, S. (2014). Myocardial extracellular matrix: an ever-changing and diverse entity. Circ. Res. 114, 872-888. doi: 10.1161/circresaha.114.302533

Rohde, D., Schon, C., Boerries, M., Didrihsone, I., Ritterhoff, J., Kubatzky, K. F., et al. (2014). S100Al is released from ischemic cardiomyocytes and signals myocardial damage via Toll-like receptor 4. EMBO Mol. Med. 6, 778-794. doi: $10.15252 / \mathrm{emmm} .201303498$

Russell, J. L., Goetsch, S. C., Gaiano, N. R., Hill, J. A., Olson, E. N., and Schneider, J. W. (2011). A dynamic notch injury response activates epicardium and contributes to fibrosis repair. Circ. Res. 108, 51-59. doi: 10.1161/circresaha.110. 233262

Sandanger, O., Ranheim, T., Vinge, L. E., Bliksoen, M., Alfsnes, K., Finsen, A. V., et al. (2013). The NLRP3 inflammasome is up-regulated in cardiac fibroblasts and mediates myocardial ischaemia-reperfusion injury. Cardiovasc. Res. 99, 164-174. doi: 10.1093/cvr/cvt091

Sandstedt, J., Sandstedt, M., Lundqvist, A., Jansson, M., Sopasakis, V. R., Jeppsson, A., et al. (2019). Human cardiac fibroblasts isolated from patients with severe heart failure are immune-competent cells mediating an inflammatory response. Cytokine 113, 319-325. doi: 10.1016/j.cyto.2018.09.021

Sano, M., Fukuda, K., Kodama, H., Pan, J., Saito, M., Matsuzaki, J., et al. (2000). Interleukin-6 family of cytokines mediate angiotensin II-induced cardiac hypertrophy in rodent cardiomyocytes. J. Biol. Chem. 275, 29717-29723. doi: $10.1074 /$ jbc.m003128200

Sansbury, B. E., and Spite, M. (2016). Resolution of acute inflammation and the role of resolvins in immunity, thrombosis, and vascular biology. Circ. Res. 119, 113-130. doi: 10.1161/circresaha.116.307308

Santiago, J. J., Dangerfield, A. L., Rattan, S. G., Bathe, K. L., Cunnington, R. H., Raizman, J. E., et al. (2010). Cardiac fibroblast to myofibroblast differentiation in vivo and in vitro: expression of focal adhesion components in neonatal and adult rat ventricular myofibroblasts. Dev. Dyn. 239, 1573-1584. doi: 10.1002/ dvdy. 22280

Savvatis, K., Pappritz, K., Becher, P. M., Lindner, D., Zietsch, C., Volk, H. D., et al. (2014). Interleukin-23 deficiency leads to impaired wound healing and adverse prognosis after myocardial infarction. Circ. Heart Fail. 7, 161-171. doi: 10.1161/circheartfailure.113.000604

Saxena, A., Chen, W., Su, Y., Rai, V., Uche, O. U., Li, N., et al. (2013). IL-1 induces proinflammatory leukocyte infiltration and regulates fibroblast phenotype in the infarcted myocardium. J. Immunol. 191, 4838-4848. doi: 10.4049/ jimmunol.1300725

Schaefer, L., Babelova, A., Kiss, E., Hausser, H. J., Baliova, M., Krzyzankova, M., et al. (2005). The matrix component biglycan is proinflammatory and signals through Toll-like receptors 4 and 2 in macrophages. J. Clin. Invest. 115, 2223-2233. doi: $10.1172 /$ jci23755

Scheibner, K. A., Lutz, M. A., Boodoo, S., Fenton, M. J., Powell, J. D., and Horton, M. R. (2006). Hyaluronan fragments act as an endogenous danger signal by engaging TLR2. J. Immunol. 177, 1272-1281. doi: 10.4049/jimmunol.177.2. 1272

Serhan, C. N., Chiang, N., and Van Dyke, T. E. (2008). Resolving inflammation: dual anti-inflammatory and pro-resolution lipid mediators. Nat. Rev. Immunol. 8, 349-361. doi: 10.1038/nri2294

Shiota, N., Rysa, J., Kovanen, P. T., Ruskoaho, H., Kokkonen, J. O., and Lindstedt, K. A. (2003). A role for cardiac mast cells in the pathogenesis of hypertensive 
heart disease. J. Hypertens. 21, 1935-1944. doi: 10.1097/00004872-20031000000022

Simpson, P. J., Todd, R. F. III, Fantone, J. C., Mickelson, J. K., Griffin, J. D., and Lucchesi, B. R. (1988). Reduction of experimental canine myocardial reperfusion injury by a monoclonal antibody (anti-Mol, anti-CD11b) that inhibits leukocyte adhesion. J. Clin. Invest. 81, 624-629. doi: 10.1172/jci113364

Siwik, D. A., Chang, D. L., and Colucci, W. S. (2000). Interleukin-1beta and tumor necrosis factor-alpha decrease collagen synthesis and increase matrix metalloproteinase activity in cardiac fibroblasts in vitro. Circ. Res. 86, 12591265. doi: 10.1161/01.res.86.12.1259

Siwik, D. A., and Colucci, W. S. (2004). Regulation of matrix metalloproteinases by cytokines and reactive oxygen/nitrogen species in the myocardium. Heart Fail. Rev. 9, 43-51. doi: 10.1023/b:hrev.0000011393.40674.13

Siwik, D. A., Pagano, P. J., and Colucci, W. S. (2001). Oxidative stress regulates collagen synthesis and matrix metalloproteinase activity in cardiac fibroblasts. Am. J. Physiol. Cell Physiol. 280, C53-C60.

Smart, N., Mojet, M. H., Latchman, D. S., Marber, M. S., Duchen, M. R., and Heads, R. J. (2006). IL-6 induces PI 3-kinase and nitric oxide-dependent protection and preserves mitochondrial function in cardiomyocytes. Cardiovasc. Res. 69, 164-177. doi: 10.1016/j.cardiores.2005.08.017

Sobirin, M. A., Kinugawa, S., Takahashi, M., Fukushima, A., Homma, T., Ono, $\mathrm{T}$., et al. (2012). Activation of natural killer $\mathrm{T}$ cells ameliorates postinfarct cardiac remodeling and failure in mice. Circ. Res. 111, 1037-1047. doi: 10.1161/ circresaha.112.270132

Soehnlein, O., and Lindbom, L. (2010). Phagocyte partnership during the onset and resolution of inflammation. Nat. Rev. Immunol. 10, 427-439. doi: 10.1038/ nri2779

Sofat, N., Robertson, S. D., and Wait, R. (2012). Fibronectin III 13-14 domains induce joint damage via Toll-like receptor 4 activation and synergize with interleukin-1 and tumour necrosis factor. J. Innate Immun. 4, 69-79. doi: $10.1159 / 000329632$

Somasundaram, P., Ren, G., Nagar, H., Kraemer, D., Mendoza, L., Michael, L. H., et al. (2005). Mast cell tryptase may modulate endothelial cell phenotype in healing myocardial infarcts. J. Pathol. 205, 102-111. doi: 10.1002/path.1690

Song, J., Wu, C., Zhang, X., and Sorokin, L. M. (2013). In vivo processing of CXCL5 (LIX) by matrix metalloproteinase (MMP)-2 and MMP-9 promotes early neutrophil recruitment in IL-1beta-induced peritonitis. J. Immunol. 190, 401-410. doi: 10.4049/jimmunol.1202286

Sousa, A. M., Liu, T., Guevara, O., Stevens, J., Fanburg, B. L., Gaestel, M., et al. (2007). Smooth muscle alpha-actin expression and myofibroblast differentiation by TGFbeta are dependent upon MK2. J. Cell Biochem. 100, 1581-1592. doi: $10.1002 /$ jcb. 21154

Sperr, W. R., Bankl, H. C., Mundigler, G., Klappacher, G., Grossschmidt, K., Agis, H., et al. (1994). The human cardiac mast cell: localization, isolation, phenotype, and functional characterization. Blood 84, 3876-3884. doi: 10.1182/blood.v84. 11.3876.bloodjournal84113876

Squires, C. E., Escobar, G. P., Payne, J. F., Leonardi, R. A., Goshorn, D. K., Sheats, N. J., et al. (2005). Altered fibroblast function following myocardial infarction. J. Mol. Cell Cardiol. 39, 699-707. doi: 10.1016/j.yjmcc.2005.07.008

Stark, M. A., Huo, Y., Burcin, T. L., Morris, M. A., Olson, T. S., and Ley, K. (2005). Phagocytosis of apoptotic neutrophils regulates granulopoiesis via IL-23 and IL-17. Immunity 22, 285-294. doi: 10.1016/j.immuni.2005.01.011

Sugano, M., Tsuchida, K., Hata, T., and Makino, N. (2004). In vivo transfer of soluble TNF-alpha receptor 1 gene improves cardiac function and reduces infarct size after myocardial infarction in rats. FASEB J. 18, 911-913. doi: 10.1096/fj.03-1148fje

Summers, C., Rankin, S. M., Condliffe, A. M., Singh, N., Peters, A. M., and Chilvers, E. R. (2010). Neutrophil kinetics in health and disease. Trends Immunol. 31, 318-324. doi: 10.1016/j.it.2010.05.006

Sun, M., Dawood, F., Wen, W. H., Chen, M., Dixon, I., Kirshenbaum, L. A., et al. (2004). Excessive tumor necrosis factor activation after infarction contributes to susceptibility of myocardial rupture and left ventricular dysfunction. Circulation 110, 3221-3228. doi: 10.1161/01.cir.0000147233.103 18.23

Suzuki, K., Murtuza, B., Smolenski, R. T., Sammut, I. A., Suzuki, N., Kaneda, Y., et al. (2001). Overexpression of interleukin-1 receptor antagonist provides cardioprotection against ischemia-reperfusion injury associated with reduction in apoptosis. Circulation 104(12 Suppl. 1), I303-I308.
Swirski, F. K., Nahrendorf, M., Etzrodt, M., Wildgruber, M., Cortez-Retamozo, V., Panizzi, P., et al. (2009). Identification of splenic reservoir monocytes and their deployment to inflammatory sites. Science $325,612-616$. doi: 10.1126/science. 1175202

Takemura, G., Ohno, M., Hayakawa, Y., Misao, J., Kanoh, M., Ohno, A., et al. (1998). Role of apoptosis in the disappearance of infiltrated and proliferated interstitial cells after myocardial infarction. Circ. Res. 82, 1130-1138. doi: 10.1161/01.res.82.11.1130

Tarzami, S. T., Cheng, R., Miao, W., Kitsis, R. N., and Berman, J. W. (2002). Chemokine expression in myocardial ischemia: MIP-2 dependent MCP-1 expression protects cardiomyocytes from cell death. J. Mol. Cell Cardiol. 34, 209-221. doi: 10.1006/jmcc.2001.1503

Tarzami, S. T., Miao, W., Mani, K., Lopez, L., Factor, S. M., Berman, J. W., et al. (2003). Opposing effects mediated by the chemokine receptor CXCR2 on myocardial ischemia-reperfusion injury: recruitment of potentially damaging neutrophils and direct myocardial protection. Circulation 108, 2387-2392. doi: 10.1161/01.cir.0000093192.72099.9a

Teekakirikul, P., Eminaga, S., Toka, O., Alcalai, R., Wang, L., Wakimoto, H., et al. (2010). Cardiac fibrosis in mice with hypertrophic cardiomyopathy is mediated by non-myocyte proliferation and requires Tgf-beta. J. Clin. Invest. 120, 3520-3529. doi: 10.1172/jci42028

Torre-Amione, G., Anker, S. D., Bourge, R. C., Colucci, W. S., Greenberg, B. H., Hildebrandt, P., et al. (2008). Results of a non-specific immunomodulation therapy in chronic heart failure (ACCLAIM trial): a placebo-controlled randomised trial. Lancet 371, 228-236. doi: 10.1016/s0140-6736(08)60134-8

Travers, J. G., Kamal, F. A., Robbins, J., Yutzey, K. E., and Blaxall, B. C. (2016). Cardiac fibrosis: the fibroblast awakens. Circ. Res. 118, 1021-1040. doi: 10.1161/ circresaha.115.306565

Tschumperlin, D. J. (2013). Fibroblasts and the ground they walk on. Physiology 28, 380-390. doi: 10.1152/physiol.00024.2013

Turner, N. A. (2016). Inflammatory and fibrotic responses of cardiac fibroblasts to myocardial damage associated molecular patterns (DAMPs). J. Mol. Cell Cardiol. 94, 189-200. doi: 10.1016/j.yjmcc.2015.11.002

Turner, N. A., Das, A., Warburton, P., O’Regan, D. J., Ball, S. G., and Porter, K. E. (2009). Interleukin-1alpha stimulates proinflammatory cytokine expression in human cardiac myofibroblasts. Am. J. Physiol. Heart Circ. Physiol. 297, H1117H1127.

Urata, H., Healy, B., Stewart, R. W., Bumpus, F. M., and Husain, A. (1990a). Angiotensin II-forming pathways in normal and failing human hearts. Circ. Res. 66, 883-890. doi: 10.1161/01.res.66.4.883

Urata, H., Kinoshita, A., Misono, K. S., Bumpus, F. M., and Husain, A. (1990b). Identification of a highly specific chymase as the major angiotensin II-forming enzyme in the human heart. J. Biol. Chem. 265, 22348-22357.

van Amerongen, M. J., Bou-Gharios, G., Popa, E., van Ark, J., Petersen, A. H., van Dam, G. M., et al. (2008). Bone marrow-derived myofibroblasts contribute functionally to scar formation after myocardial infarction. J. Pathol. 214, 377386. doi: $10.1002 /$ path. 2281

van Amerongen, M. J., Harmsen, M. C., van Rooijen, N., Petersen, A. H., and van Luyn, M. J. (2007). Macrophage depletion impairs wound healing and increases left ventricular remodeling after myocardial injury in mice. Am. J. Pathol. 170, 818-829. doi: 10.2353/ajpath.2007.060547

Van den Steen, P. E., Proost, P., Wuyts, A., Van Damme, J., and Opdenakker, G. (2000). Neutrophil gelatinase B potentiates interleukin- 8 tenfold by aminoterminal processing, whereas it degrades CTAP-III, PF-4, and GRO-alpha and leaves RANTES and MCP-2 intact. Blood 96, 2673-2681. doi: 10.1182/ blood.v96.8.2673

Van der Borght, K., Scott, C. L., Nindl, V., Bouche, A., Martens, L., Sichien, D., et al. (2017). Myocardial infarction primes autoreactive T cells through activation of dendritic cells. Cell Rep. 18, 3005-3017. doi: 10.1016/j.celrep.2017.02.079

Van Tassell, B. W., Raleigh, J. M., and Abbate, A. (2015). Targeting interleukin-1 in heart failure and inflammatory heart disease. Curr. Heart Fail. Rep. 12, 33-41. doi: 10.1007/s11897-014-0231-7

Varda-Bloom, N., Leor, J., Ohad, D. G., Hasin, Y., Amar, M., Fixler, R., et al. (2000). Cytotoxic T lymphocytes are activated following myocardial infarction and can recognize and kill healthy myocytes in vitro. J. Mol. Cell Cardiol. 32, 2141-2149. doi: 10.1006/jmcc.2000.1261

Vasilyev, N., Williams, T., Brennan, M. L., Unzek, S., Zhou, X., Heinecke, J. W., et al. (2005). Myeloperoxidase-generated oxidants modulate left ventricular 
remodeling but not infarct size after myocardial infarction. Circulation 112, 2812-2820. doi: 10.1161/circulationaha. 105.542340

Virag, J. I., and Murry, C. E. (2003). Myofibroblast and endothelial cell proliferation during murine myocardial infarct repair. Am. J. Pathol. 163, 2433-2440. doi: 10.1016/s0002-9440(10)63598-5

Wang, J., Duan, Y., Sluijter, J. P., and Xiao, J. (2019). Lymphocytic subsets play distinct roles in heart diseases. Theranostics 9, 4030-4046. doi: 10.7150/thno. 33112

Wang, J., Seo, M. J., Deci, M. B., Weil, B. R., Canty, J. M., and Nguyen, J. (2018). Effect of CCR2 inhibitor-loaded lipid micelles on inflammatory cell migration and cardiac function after myocardial infarction. Int. J. Nanomed. 13, 6441-6451. doi: 10.2147/ijn.s178650

Wang, S., Voisin, M. B., Larbi, K. Y., Dangerfield, J., Scheiermann, C., Tran, M., et al. (2006). Venular basement membranes contain specific matrix protein low expression regions that act as exit points for emigrating neutrophils. J. Exp. Med. 203, 1519-1532. doi: 10.1084/jem.20051210

Wang, S., Wilkes, M. C., Leof, E. B., and Hirschberg, R. (2005). Imatinib mesylate blocks a non-Smad TGF-beta pathway and reduces renal fibrogenesis in vivo. FASEB J. 19, 1-11. doi: 10.1096/fj.04-2370com

Wei, C. C., Lucchesi, P. A., Tallaj, J., Bradley, W. E., Powell, P. C., and Dell'Italia, L. J. (2003). Cardiac interstitial bradykinin and mast cells modulate pattern of LV remodeling in volume overload in rats. Am. J. Physiol. Heart Circ. Physiol. 285, H784-H792.

Weirather, J., Hofmann, U. D., Beyersdorf, N., Ramos, G. C., Vogel, B., Frey, A., et al. (2014). Foxp3+ CD4+ T cells improve healing after myocardial infarction by modulating monocyte/macrophage differentiation. Circ. Res. 115, 55-67. doi: 10.1161/circresaha.115.303895

Wenzel, P., Knorr, M., Kossmann, S., Stratmann, J., Hausding, M., Schuhmacher, S., et al. (2011). Lysozyme M-positive monocytes mediate angiotensin II-induced arterial hypertension and vascular dysfunction. Circulation 124, 1370-1381. doi: 10.1161/circulationaha.111.034470

Williams, M. R., Azcutia, V., Newton, G., Alcaide, P., and Luscinskas, F. W. (2011). Emerging mechanisms of neutrophil recruitment across endothelium. Trends Immunol. 32, 461-469. doi: 10.1016/j.it.2011.06.009

Xu, J., Lin, S. C., Chen, J., Miao, Y., Taffet, G. E., Entman, M. L., et al. (2011). CCR2 mediates the uptake of bone marrow-derived fibroblast precursors in angiotensin II-induced cardiac fibrosis. Am. J. Physiol. Heart Circ. Physiol. 301, H538-H547.

Xue, J., Schmidt, S. V., Sander, J., Draffehn, A., Krebs, W., Quester, I., et al. (2014). Transcriptome-based network analysis reveals a spectrum model of human macrophage activation. Immunity 40, 274-288. doi: 10.1016/j.immuni.2014.01. 006

Yan, X., Anzai, A., Katsumata, Y., Matsuhashi, T., Ito, K., Endo, J., et al. (2013). Temporal dynamics of cardiac immune cell accumulation following acute myocardial infarction. J. Mol. Cell Cardiol. 62, 24-35. doi: 10.1016/j.yjmcc. 2013.04.023

Yan, X., Shichita, T., Katsumata, Y., Matsuhashi, T., Ito, H., Ito, K., et al. (2012). Deleterious effect of the IL-23/IL-17A axis and gammadeltaT cells on left ventricular remodeling after myocardial infarction. J. Am. Heart Assoc. $1: \mathrm{e} 004408$

Yang, Z., Zingarelli, B., and Szabo, C. (2000). Crucial role of endogenous interleukin-10 production in myocardial ischemia/reperfusion injury. Circulation 101, 1019-1026. doi: 10.1161/01.cir.101.9. 1019

Yano, T., Miura, T., Ikeda, Y., Matsuda, E., Saito, K., Miki, T., et al. (2005). Intracardiac fibroblasts, but not bone marrow derived cells, are the origin of myofibroblasts in myocardial infarct repair. Cardiovasc. Pathol. 14, 241-246. doi: 10.1016/j.carpath.2005.05.004

Yokoyama, T., Vaca, L., Rossen, R. D., Durante, W., Hazarika, P., and Mann, D. L. (1993). Cellular basis for the negative inotropic effects of tumor necrosis factor-alpha in the adult mammalian heart. J. Clin. Invest. 92, 2303-2312. doi: 10.1172/jci116834

Ytrehus, K., Hulot, J. S., Perrino, C., Schiattarella, G. G., and Madonna, R. (2018). Perivascular fibrosis and the microvasculature of the heart. Still hidden secrets of pathophysiology? Vascul. Pharmacol. 107, 78-83. doi: 10.1016/j.vph.2018. 04.007

Zarbock, A., Ley, K., McEver, R. P., and Hidalgo, A. (2011). Leukocyte ligands for endothelial selectins: specialized glycoconjugates that mediate rolling and signaling under flow. Blood 118, 6743-6751. doi: 10.1182/blood-2011-07343566

Zeisberg, E. M., Tarnavski, O., Zeisberg, M., Dorfman, A. L., McMullen, J. R., Gustafsson, E., et al. (2007). Endothelial-to-mesenchymal transition contributes to cardiac fibrosis. Nat. Med. 13, 952-961.

Zhang, W., Chancey, A. L., Tzeng, H. P., Zhou, Z., Lavine, K. J., Gao, F., et al. (2011). The development of myocardial fibrosis in transgenic mice with targeted overexpression of tumor necrosis factor requires mast cell-fibroblast interactions. Circulation 124, 2106-2116. doi: 10.1161/circulationaha.111. 052399

Zhang, W., Lavine, K. J., Epelman, S., Evans, S. A., Weinheimer, C. J., Barger, P. M., et al. (2015). Necrotic myocardial cells release damage-associated molecular patterns that provoke fibroblast activation in vitro and trigger myocardial inflammation and fibrosis in vivo. J. Am. Heart Assoc. 4:e001993.

Zhang, Y., Wang, J. H., Zhang, Y. Y., Wang, Y. Z., Wang, J., Zhao, Y., et al. (2016). Deletion of interleukin-6 alleviated interstitial fibrosis in streptozotocininduced diabetic cardiomyopathy of mice through affecting TGFbetal and miR-29 pathways. Sci. Rep. 6:23010.

Zhao, L., and Eghbali-Webb, M. (2001). Release of pro- and anti-angiogenic factors by human cardiac fibroblasts: effects on DNA synthesis and protection under hypoxia in human endothelial cells. Biochim. Biophys. Acta 1538, 273-282. doi: 10.1016/s0167-4889(01)00078-7

Zouggari, Y., Ait-Oufella, H., Bonnin, P., Simon, T., Sage, A. P., Guerin, C., et al. (2013). B lymphocytes trigger monocyte mobilization and impair heart function after acute myocardial infarction. Nat. Med. 19, 1273-1280. doi: 10.1038/nm. 3284

Zymek, P., Bujak, M., Chatila, K., Cieslak, A., Thakker, G., Entman, M. L., et al. (2006). The role of platelet-derived growth factor signaling in healing myocardial infarcts. J. Am. Coll. Cardiol. 48, 2315-2323. doi: 10.1016/j.jacc. 2006.07.060

Zymek, P., Nah, D. Y., Bujak, M., Ren, G., Koerting, A., Leucker, T., et al. (2007). Interleukin-10 is not a critical regulator of infarct healing and left ventricular remodeling. Cardiovasc. Res. 74, 313-322. doi: 10.1016/j.cardiores.2006.11.028

Conflict of Interest: The authors declare that the research was conducted in the absence of any commercial or financial relationships that could be construed as a potential conflict of interest.

Copyright (c) 2020 Thomas and Grisanti. This is an open-access article distributed under the terms of the Creative Commons Attribution License (CC BY). The use, distribution or reproduction in other forums is permitted, provided the original author(s) and the copyright owner(s) are credited and that the original publication in this journal is cited, in accordance with accepted academic practice. No use, distribution or reproduction is permitted which does not comply with these terms. 